REVIEW

\title{
Genetics of familial intrahepatic cholestasis syndromes
}

\author{
S W C van Mil, R H J Houwen, L W J Klomp
}

J Med Genet 2005;42:449-463. doi: 10.1136/jmg.2004.026187

Bile acids and bile salts have essential functions in the liver and in the small intestine. Their synthesis in the liver provides a metabolic pathway for the catabolism of cholesterol and their detergent properties promote the solubilisation of essential nutrients and vitamins in the small intestine. Inherited conditions that prevent the synthesis of bile acids or their excretion cause cholestasis, or impaired bile flow. These disorders generally lead to severe human liver disease, underscoring the essential role of bile acids in metabolism. Recent advances in the elucidation of gene defects underlying familial cholestasis syndromes has greatly increased knowledge about the process of bile flow. The expression of key proteins involved in bile flow is tightly regulated by transcription factors of the nuclear hormone receptor family, which function as sensors of bile acids and cholesterol. Here we review the genetics of familial cholestasis disorders, the functions of the affected genes in bile flow, and their regulation by bile acids and cholesterol.

See end of article for authors' affiliations

Correspondence to: Leo W J Klomp, University Medical Center Utrecht, Room KCO2.069.1, Lundlaan 6, 3584 EA Utrecht, The Netherlands; l.klomp@azu.nl

Revised version received 5 August 2004 Accepted for publication 24 August 2004
$E_{h}^{a}$ ach day, approximately $500 \mathrm{mg}$ of bile acids are synthesised from cholesterol in the adult human liver. Newly synthesised bile acids are conjugated with either glycine or taurine and subsequently secreted into bile and stored in the gallbladder. Biliary secretion of bile salts against a concentration gradient requires the hydrolysis of adenosine triphosphate (ATP) and this process provides the driving force for bile flow. Because of their detergent properties, bile acids are inherently cytotoxic, and hence it is important that intracellular levels of bile acids are tightly regulated. This is largely accomplished by transcriptional regulation of genes encoding proteins involved in bile acid synthesis and transport.

Cholestasis, or impaired bile flow, is one of the most common and devastating manifestations of liver disease. Cholestasis is clinically characterised by elevated plasma concentrations of biliary constituents, resulting in jaundice, malabsorption of fats and fat-soluble vitamins and, in many cases, progressive liver damage. Both acquired and hereditary forms of cholestasis have been described. Familial intrahepatic cholestasis syndromes can be caused by a deficiency either in bile acid synthesis or in the transport of bile salts into bile. Elucidation of the gene defects underlying these hereditary cholestasis syndromes is of critical importance for our understanding of hereditary cholestasis and, consequently, for our knowledge of the process of bile acid synthesis and transport.
During the last decade, many loci underlying intrahepatic cholestasis have been mapped, the genes have been identified, and protein functions have been studied. Taken together with the recent exciting discovery of nuclear hormone receptors that act as bile acid sensors by transcriptional regulation of key enzymes and transporters in bile acid metabolism, these studies have allowed a detailed understanding of the molecular mechanisms and regulation of bile formation. This review summarises recent insights into the genetics of familial intrahepatic cholestasis syndromes and the functions and regulation of the affected proteins. We have divided most familial cholestasis syndromes in classes comprising bile acid synthesis defects and bile salt transport defects because the genetic disorders in these different classes have common aspects in disease outcome and possible treatment, which will be discussed below. We have classified a defect in bile acid conjugation as a synthesis defect and we tentatively consider familial intrahepatic cholestasis type l (FICl) disease as a bile salt transport defect, although the exact mode by which FICl disease causes intrahepatic cholestasis is unknown.

\section{PHYSIOLOGY AND CELL BIOLOGY OF BILE FORMATION}

Biliary excretion of different compounds is an important function of the liver. Synthesis and

Abbreviations: $A B C$, ATP-binding cassette; AKRIDI, $\triangle 4$-3-oxosteroid- $5 \beta$ reductase; AMACR, 2-methylacylCoA racemase; ASBT, apical sodium-dependent bile salt transporter; ATP, adenosine triphosphate; BAAT, bile acid CoA:amino acid $N$-acyltransferase; BRIC, benign recurrent intrahepatic cholestasis; BSEP, bile salt export

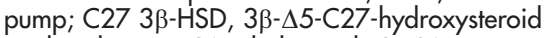
oxidoreductase; CA, cholic acid; CDCA,

chenodeoxycholic acid; CEA, carcinoembryonic antigen; CTX, cerebrotendinous xanthomatosis; DCA, deoxycholic acid; DHCA, dihydroxycholestanoic acid; FHCA, familial hypercholanaemia; $\mathrm{FICl}$, familial intrahepatic cholestasis type 1; FXR, farnesoid X receptor; GFC, Greenland familial cholestasis; GGT, gamma-glutamyl transpeptidase; GPI, glycosyl phosphatidyl inositol; HSD 3B7, 3 $\beta-\triangle 5$-C27-hydroxysteroid oxidoreductase; $I B A B P$, ileal bile acid binding protein; ICP, intrahepatic cholestasis of pregnancy; LCA, lithocholic acid; LCS, lymphoedema-cholestasis syndrome; $L X R \alpha$, liver $X$ receptor $\alpha ; \mathrm{mEH}$, microsomal epoxide hydrolase; NAICC, North American Indian childhood cirrhosis; NTCP, sodium-dependent taurocholate protein; OATP, organic anion transporter; PBAM, primary bile acid malabsorption; PC, phosphatidyl choline; PFIC, progressive familial intrahepatic cholestasis; PXR, pregnane $X$ receptor; SHP, short heterodimeric partner; tASBT, truncated form of ASBT; THCA,

trihydroxycholestanoic acid; TJP2, tight junction protein 2; UDCA, ursodeoxycholic acid; VDR, vitamin D nuclear receptor 
transport of bile acids are essential for efficient bile flow. Bile acids are synthesised in the liver and stored in the gallbladder. Upon digestion of a meal, bile salts are delivered to the lumen of the small intestine where they act as emulsifiers of dietary lipids, cholesterol, and fat-soluble vitamins. Bile salts are converted by intestinal bacteria, transported from the intestine to the liver via the portal circulation, and subsequently resecreted into bile. Approximately $95 \%$ of bile salts are recovered in the gut during each cycle of this enterohepatic circulation, and the $5 \%$ that are lost via the faeces are replaced by de novo synthesis in the liver (fig 1A).

In fig $1 \mathrm{~B}$, some important transport proteins involved in the enterohepatic circulation of bile salts are depicted schematically. As can be seen from this figure, the enterohepatic circulation of bile salts requires regulated vectorial transport of bile salts in polarised epithelial cells, such as the hepatocyte and the enterocyte. The bile salt export pump (BSEP) mediates secretion of bile salts from the apical domains of hepatocytes into bile. In the intestine, the apical sodium-dependent bile salt transporter (ASBT) is responsible for reabsorption of bile acids at the brush border, while the ileal bile acid binding protein (IBABP) is thought to transport bile acids through the cytoplasm of the enterocytes to the basolateral membrane. A truncated form of ASBT (tASBT) transports bile acids from the enterocytes into the blood. At the basolateral membrane of the hepatocytes, the sodium-dependent taurocholate protein (NTCP) and to a lesser extent the organic anion transporter family (OATP) are needed for the uptake of bile acids. It is incompletely understood how the biliary epithelium, which consists of cholangiocytes, functionally participates in bile salt transport. It is known that ASBT is also expressed at the apical membranes of cholangiocytes. In cultured cholangiocytes, taurocholate is transported from the apical to the basolateral membrane in a sodium dependent fashion. These findings provided indirect evidence for a cholehepatic shunt pathway for bile salts, which is further discussed elsewhere. ${ }^{12}$

\section{BILE ACID SYNTHESIS}

Bile acids are formed from cholesterol in the hepatocytes. In humans two bile acids are formed: cholic acid (CA), a trihydroxy-bile acid with hydroxyl groups at C-3, C-7, and C12; and chenodeoxycholic acid (CDCA), a dihydroxy-bile acid with hydroxyl groups at C-3 and C-7 (fig 2). Bile acid biosynthesis is quite complex and synthesis of the full complement of bile acids requires 17 enzymes, which involves the addition of hydroxyl groups to the ring structure of cholesterol and the oxidation and shortening of the side chain $^{3}$ (figs 2 and 3). In order to survive the low $\mathrm{pH}$ in the intestine, bile acids are conjugated to glycine or taurine, forming bile salts. The enzymes required for bile acid biosynthesis are located in different cell organelles; the addition of hydroxyl groups mainly occurs in the endoplasmic reticulum, whereas further ring structure modifications are performed in the cytoplasm. Side chain modification and conjugation are mainly performed in the peroxisomes. ${ }^{3}$ The hepatocyte, therefore, faces an enormous challenge in transporting intermediates throughout its interior, but the responsible transport mechanisms are unknown.

CA and CDCA are termed primary bile acids because they are synthesised de novo in hepatocytes. There are two main pathways that lead to the formation of bile acids: the classical pathway, which results in CA formation, and the acidic pathway, which is responsible for CDCA formation. In the intestine, bile salts undergo deconjugation by bacterial enzymes to form an unconjugated bile acid and glycine or taurine. Some of these unconjugated bile acids are reabsorbed in the ileum and returned to the liver. When primary bile acids enter the colon, the hydroxyl group at C-7 is removed by anaerobic bacteria, and 7-deoxy bile acids are formed. By this process, CA is converted to deoxycholic acid (DCA) and CDCA is converted to lithocholic acid (LCA). DCA and LCA are called secondary bile acids because they are formed from primary bile acids in the intestine. Both are reabsorbed in the colon by an unknown mechanism and returned to the liver. In the liver, DCA is conjugated with glycine or taurine and circulates with the primary bile acids. In contrast, LCA is conjugated with glycine or taurine and additionally sulfated at the C-3 position. These sulfated bile salts are secreted into bile but are not efficiently absorbed from the intestine and are therefore eliminated from the body via the faeces. ${ }^{45}$

Bile acids are cytotoxic when their concentrations increase to abnormally high levels intracellularly or extracellularly and this cytotoxicity is strongly dependent on their physicochemical properties. CA is the most hydrophilic bile acid with three hydroxy groups and is therefore less cytotoxic, whereas DCA and CDCA are more harmful because they only have two hydroxyl groups. LCA is the most cytotoxic naturally occurring bile acid with only one hydroxyl group. UDCA, a naturally occurring bile acid in black bears but detected in humans only in trace amounts, is devoid of cytotoxic properties; this bile acid is relatively hydrophilic, although it is a di-hydroxy bile acid, but the hydroxyl group at C-7 is in the $\beta$ rather than the $\alpha$ configuration as in CDCA. ${ }^{6}$ UDCA is used as a therapeutic agent in many forms of cholestasis in order to partly replace the relatively cytotoxic bile salt pool in human patients. The biliary bile salt pool consists mainly of equal amounts of conjugated CA and CDCA (80\%), and more than $10 \%$ consists of conjugated DCA. Normally, only trace amounts of the conjugated forms of LCA and UDCA are present in bile. In the faeces, only DCA $(70 \%)$ and LCA $(30 \%)$ are detected.

Because of the potential cytotoxicity of bile acids, the expression of selected enzymes in the bile acid biosynthesis pathway is tightly regulated by feedback inhibition and feed forward induction processes. It is now know that the main regulatory responses are at the level of transcription and are largely mediated by nuclear hormone receptors and other transcription factors, which ensure a continuous supply of bile acids in an always-changing metabolic environment.

\section{BILE ACID SYNTHESIS DEFECTS}

Inherited mutations that impair bile acid synthesis cause a spectrum of human disease ranging from liver failure in early childhood to progressive neuropathy in adults. As discussed above, the ATP-dependent secretion of bile salts provides a hyperosmotic environment in hepatic canaliculi, which is responsible for the subsequent secretion of water, eventually resulting in bile flow. A decrease in bile acid availability, secondary to biosynthesis defects, is therefore predicted to impair bile flow. In this review, we focus on disorders that result in intrahepatic cholestasis. In fig 3, we depicted a simplified schematic representation of the bile acid synthesis pathway. Only enzymes that are implicated in disease are depicted in this figure. (For reviews of the total bile acid synthesis pathway, see Russell ${ }^{3}$ and Chiang. ${ }^{7}$ )

\section{Deficiency of $7 \alpha$-hydroxylases}

Initiation of bile acid synthesis begins with the conversion of cholesterol to $7 \alpha$-hydroxycholesterol by CYP7Al and CYP7Bl and this is the rate-limiting step in bile acid biosynthesis. CYP7Al is used in the classical pathway, while CYP7Bl is used in the acidic pathway and is preceded by $27 \alpha$ hydroxylation of cholesterol (fig 3 and reviewed in Russell ${ }^{3}$ and Chiang ${ }^{7}$. 


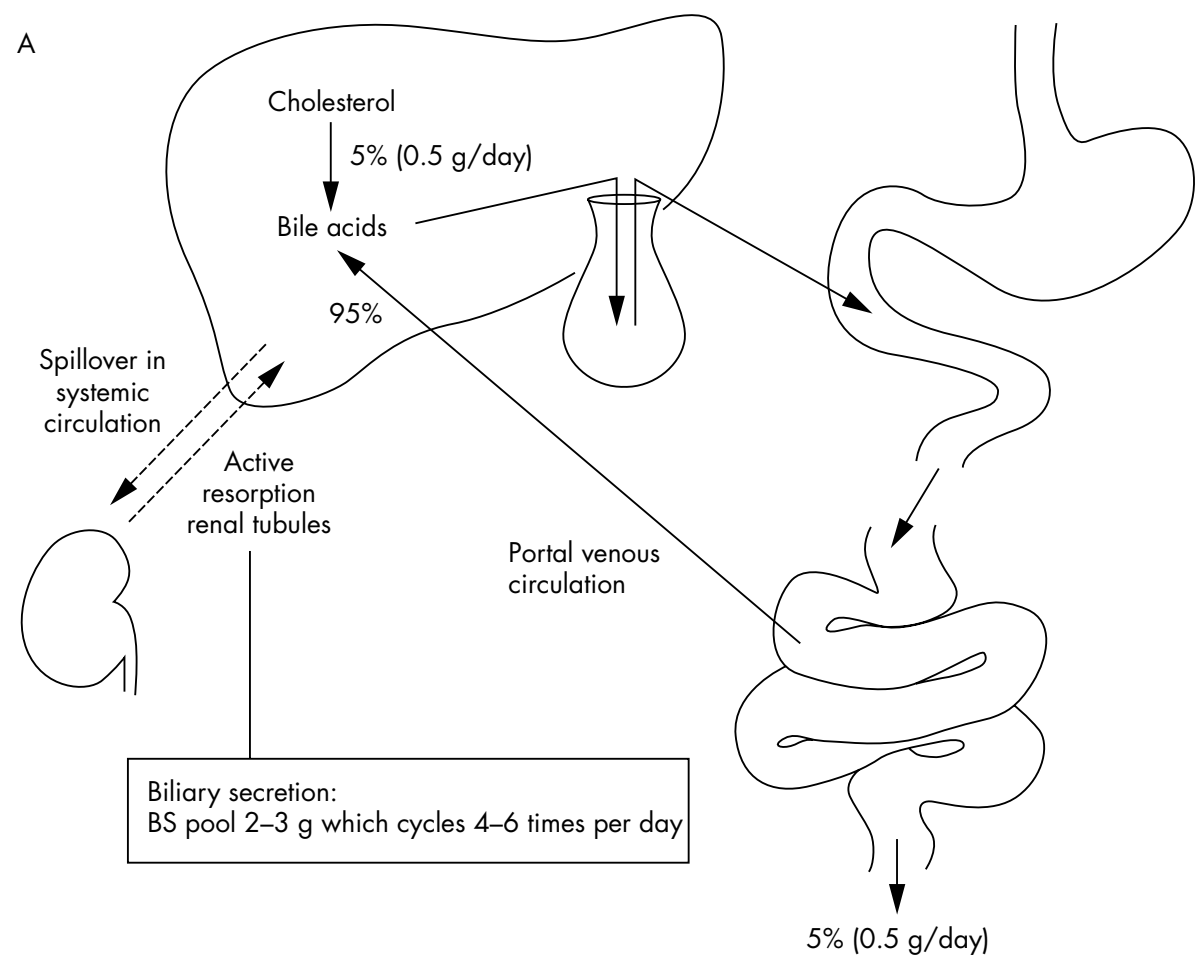

B

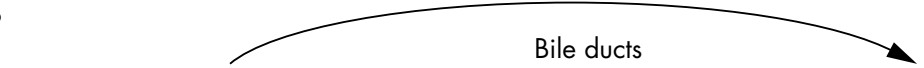

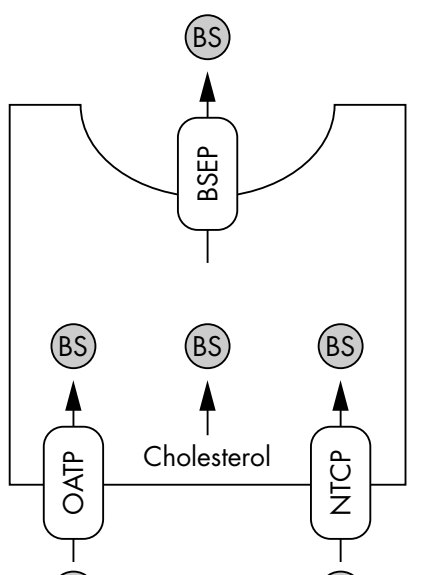

(BS)

(BS)

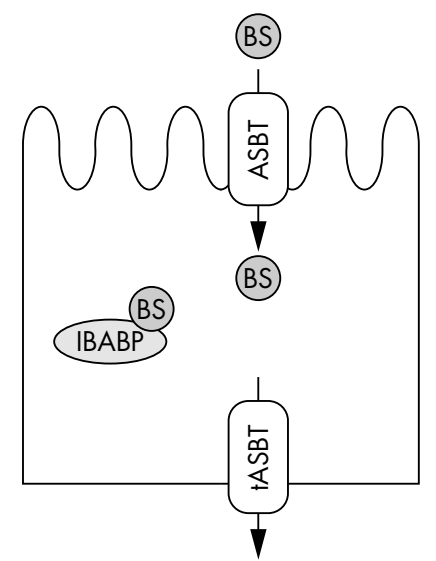

(BS)

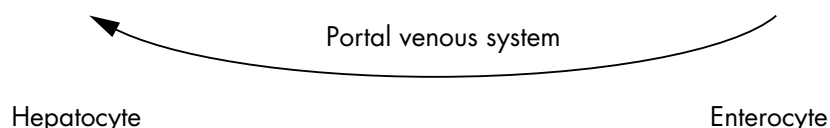

Figure 1 Schematic representation of the enterohepatic circulation of bile salts. The organs (A) and cell types and transporters (B) that are involved in the enterohepatic circulation of bile salts are depicted. For simplicity, the cholangiocytes are not presented. For further details, see text. ASBT, apical sodium-dependent bile salt transporter; BS, bile salts explained; BSEP, bile salt export pump; IBABP, ileal bile acid binding protein; NTCP, sodiumdependent taurocholate protein; OATP, organic anion transporter; tASBT, truncated form of ASBT.

\section{CYP7A1 deficiency}

Mice deficient in $7 \alpha$-hydroxylase activity were produced by targeted disruption of Cyp7a1. ${ }^{8}$ Homozygous animals appeared normal at birth but died within the first 18 days of life, unless their diet was supplemented with vitamins and

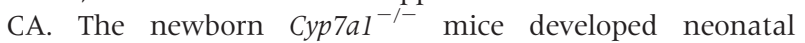
cholestasis and, due to vitamin deficiencies, oily coats, hyperkeratosis, vision defects, and behavioural irregularities. Cyp7bl starts to be expressed after weaning (at 21 days after birth) and this enzyme can probably compensate for Cyp7al deficiency after weaning, because $\mathrm{Cyp} \mathrm{Fl}^{-/-}$mice that survived through day 17 became healthy and had life spans that approximate those of wildtype mice. ${ }^{8}$

Human CYP7Al is located at chromosome 8q21.13 and currently only one human family with CYP7Al deficiency has been described. ${ }^{9}$ In three adult patients a nonsense mutation was detected in homozygous form, which resulted in the truncation of the last 91 amino acid residues. Lack of CYP7Al 


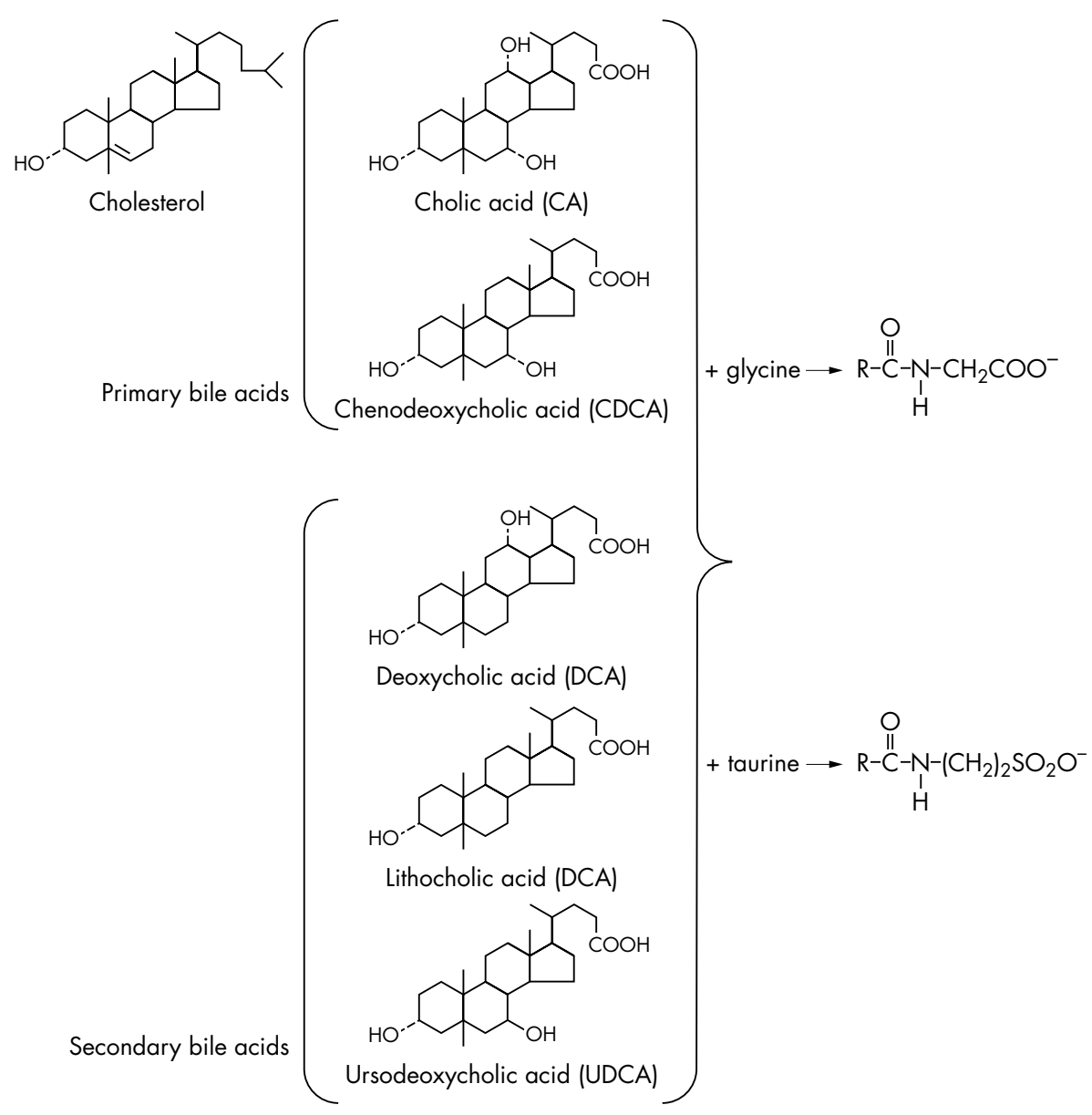

Figure 2 Chemical structure of the major bile acids present in human bile and faeces. Primary bile acids are formed in the liver, and secondary bile acids are formed in the intestine by bacterial 7-dehydroxylation of their primary bile acid precursor (deoxycholic acid and lithocholic acid). Ursodeoxycholic acid (UDCA) is formed by bacterial epimerisation of the hydroxyl group at C-7. (Adapted from Hofmann ${ }^{4}$ )

activity in vitro was confirmed using a mutant protein lacking the carboxy terminal 91 amino acid residues. Patients have hyperlipidaemia, premature coronary and peripheral vascular disease, and premature gallstone disease, together with a markedly reduced bile acid synthesis rate. The acidic bile acid synthesis pathway is upregulated. However, the severe malnutrition and neonatal cholestasis observed in mice were not present in this family. This may reflect differences in how bile acid synthesis is regulated between these two species. ${ }^{10}$

The disorder appears to be inherited in an autosomal codominant fashion because heterozygous family members had increased serum LDL cholesterol levels in comparison with their unaffected relatives.

\section{CYP7B 1 deficiency}

CYP7B1 is located at chromosome $8 \mathrm{q} 21.3$ and encodes CYP7B1, which is localised in the endoplasmic reticulum in the cells of many tissues and hydroxylates cholesterol in the acidic pathway. Setchell et al ${ }^{11}$ reported the only known case of CYP7Bl deficiency. A child of consanguineous parents presented with neonatal cholestasis and cirrhosis at 6 days of age. Primary bile acid conjugates were absent in serum, whereas the concentration of the highly toxic mono-hydroxylated $27 \alpha$-hydroxy cholesterol was 4500 -fold higher than normal. Strikingly, there were no $7 \alpha$-hydroxylated bile acids. Neither CYP7Al nor CYP7Bl hydroxylase activities were detectable in the liver of this patient, although $7 \alpha$-hydroxylase protein was present as evidenced by immunoblotting.
Sequence analysis revealed a nonsense mutation in exon 5 (of 6) of CYP7B1 but no mutations in CYP7A1. The truncated CYP7Bl protein was inactive when expressed in cells. Presumably, the accumulated $27 \alpha$-hydroxysterol reduced CYP7Al expression or activity and resulted in a complete loss of bile acid synthesis. Oral bile acid therapy did not improve the patient's condition and a liver transplantation was performed at 4.5 months of age. Acute allograft rejection occurred and the patient died 20 days after transplantation. Setchell et al ${ }^{11}$ speculate that CYP7BI mutations generally cause prenatal or early neonatal lethality, and that this single reported case represents an exception to fetal death. LiHawkins et $a l^{12}$ observed that Cyp $7 b 1$ knockout mice were phenotypically indistinguishable from healthy littermates. They concluded that the major physiological role of Cyp7bl is to inactivate oxysterols and that loss of this enzyme in the liver of mice is compensated for by an increase in the synthesis of bile acids by other pathways. Again, the differences between mice and man are presumably the result of differences in regulation of bile acid synthesis between these species. ${ }^{10}$

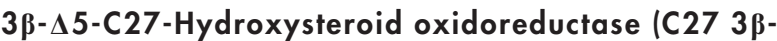 HSD or HSD3B7) deficiency}

Clayton and colleagues first reported progressive intrahepatic cholestasis due to C27 $3 \beta$-HSD enzyme deficiency in $1987^{13}$ (fig 3 and table 1). A child presented with neonatal jaundice, liver enlargement, fat-soluble vitamin deficiency, and steatorrhoea. Mass spectrometry analysis of urine and plasma 


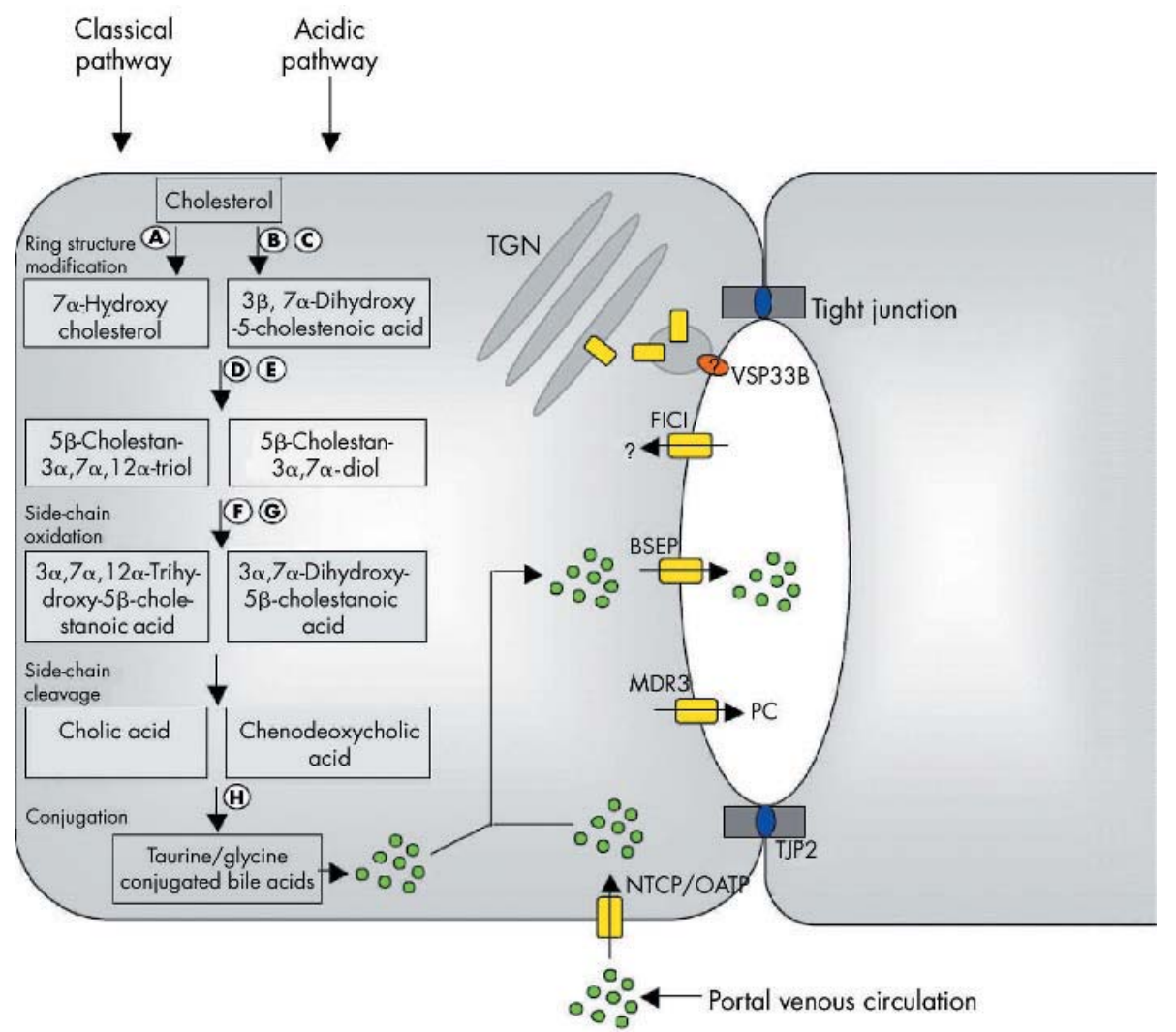

$\begin{array}{ll}\text { (A) CYP7A1 } & \text { (E) AKRID1 } \\ \text { (B) CYP27A1 } & \text { (F)AMACR } \\ \text { (C) CYP7B1 } & \text { (G) D-Bifunctional protein } \\ \text { (D) } 3 \beta-H S D & \text { (A) BAAT }\end{array}$

Figure 3 Schematic representation of proteins that are involved in bile flow in the hepatocyte. On the left side of the hepatocyte, a simplified representation of bile acid synthesis is depicted; only proteins that are known to be implicated in familial disease are depicted. At the canalicular membranes of the hepatocytes, transporters in which mutations cause cholestasis are depicted. MDR3 transports phosphatidyl choline (PC) from the inner to the outer leatlet of the plasma membrane, the BSEP transports bile salts into the bile canaliculi, and $\mathrm{FICl}$ is thought to transport aminophospholipids. Mutations in TJP2 and VSP33B are also associated with cholestatic disease. See text for further explanation.

revealed accumulation of hepatotoxic C24 and C27 steroids. C27 3 $\beta$-HSD enzyme activity was absent in cultured fibroblasts of this patient. Since then, several patients have been diagnosed with C27 $3 \beta$-HSD deficiency. ${ }^{13-15}$ It was only in 2000 that HSD3B7, which encodes C27 3 $\beta$-HSD, was cloned and mapped to chromosome 16pl1.2-12, and a homozygous mutation was found in HSD3B7 of the patient previously described by Clayton and his colleagues. ${ }^{13} 16$ This mutation resulted in truncation of the last 23 amino acid residues and elimination of enzyme activity in transfected cells. Bile acid therapy leads to increased well being, a decrease in pruritus, and a normalisation of urinary steroids in these patients. ${ }^{17}$

\section{$\Delta$ 4-3-Oxosteroid-5 $\beta$ reductase (AKR 1D 1) deficiency}

Severe intrahepatic cholestasis was observed by Setchell et al in two identical twin siblings in $1988 .{ }^{18}$ The parents were not consanguineous. Jaundice, pale stools, and dark urine were noted on the first day of life. Mass spectrometry analysis revealed markedly reduced primary bile acid synthesis and concomitant accumulation of 44-3-oxo and allo bile acids. These biochemical findings, which were identical in both infants, indicated a defect in bile acid synthesis catalysed by $\Delta 4$-3-oxosteroid-5 $\beta$ reductase (AKRIDI). The accumulating sterols are hepatotoxic and cause liver failure over time, a situation which is effectively treated with oral bile acid therapy.

Kondo et $a l^{19}$ cloned the human gene for $\Delta 4$-3-oxosteroid$5 \beta$ reductase $(A K R I D 1)$, which is located at chromosome $7 \mathrm{q} 32-33 .^{20}$ Mutation analysis in the twin patients has not been reported and currently there is no mouse model available.

\section{Other bile acid biosynthesis defects not involving intrahepatic cholestasis}

Patients have been described with Cyp27Al deficiency (fig 3 and table 1) which causes the neuropathological disorder cerebrotendinous xanthomatosis (CTX).$^{21}$ Bile acid synthesis is reduced but it is the buildup of cholesterol and cholestanol in the blood and tissues that causes xanthomata together with cardiovascular problems. In the brain, these sterols gradually disrupt the myelin sheaths surrounding neurons resulting in progressive neurological dysfunction. If diagnosed at an early age, CTX is treated efficiently with oral bile acid therapy.

Patients with 2-methylacyl-CoA racemase (AMACR) (fig 3 and table 1) deficiency accumulate pristanic acid and the bile 
Table 1 Familial intrahepatic cholestasis syndromes

\begin{tabular}{|c|c|c|c|}
\hline Disorder & Chromosome & Gene & Phenotype \\
\hline \multicolumn{4}{|l|}{ Bile acid synthesis disorders } \\
\hline CYP7A1 deficiency & $8 q 21.13$ & CYP7A1 & $\begin{array}{l}\text { Hyperlipidaemia, premature coronary and peripheral vascular } \\
\text { disease, and premature gallstone disease }\end{array}$ \\
\hline CYP7B1 deficiency & $8 q 21.3$ & CYP7B1 & Neonatal cholestasis and cirrhosis \\
\hline 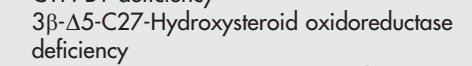 & $16 p 11.2-12$ & HSD $3 B 7$ & $\begin{array}{l}\text { Neonatal jaundice, fat-soluble vitamin deficiency, and } \\
\text { steatorrhoea }\end{array}$ \\
\hline$\Delta 4-3-O x$ osteroid- $5 \beta$ reductase deficiency & $7 q 32-33$ & AKRIDI & Intrahepatic cholestasis, jaundice, pale stools, and dark urine \\
\hline Cerebrotendinous xanthomatosis (CTX) & 2q33-qter & CYP27A1 & Xanthomatas and cardiovascular problems \\
\hline 2-Methylacyl CoA racemase deficiency & $15 p 13.2-5 q 11.1$ & $A M A C R$ & $\begin{array}{l}\text { Adult-onset sensory motor neuropathy, accumulation of pristanic } \\
\text { acids and bile acid intermediates }\end{array}$ \\
\hline D-bifunctional protein deficiency & $5 q^{2}$ & HSDI7B4 & Hepatomegaly, developmental defects, hypotonia, and seizures \\
\hline \multicolumn{4}{|l|}{ Bile acid synthesis/tight junction defect } \\
\hline $\begin{array}{l}\text { Familial hypercholanaemia } \\
\text { (FHCA) }\end{array}$ & $\begin{array}{l}9 q 12-13 \\
9 q 22-23\end{array}$ & $\begin{array}{l}\text { TJP2 } \\
\text { BAAT }\end{array}$ & $\begin{array}{l}\text { Fat malabsorption, vitamin K-deficiency, sometimes cholestasis } \\
\text { and chronic hepatitis }\end{array}$ \\
\hline \multicolumn{4}{|l|}{ Canalicular transport defects } \\
\hline $\mathrm{FICl}$ disease & $18 q 21-22$ & ATP8B 1 & $\begin{array}{l}\mathrm{PFIC1} \text { : progressive cholestasis, cirrhosis } \\
\text { BRICl: recurrent attacks of cholestasis } \\
\text { GFC: as in PFICl }\end{array}$ \\
\hline BSEP disease & $2 q 24$ & $A B C B 11$ & $\begin{array}{l}\text { PFIC2: progressive cholestasis, cirrhosis } \\
\text { BRIC2: recurrent attacks of cholestasis }\end{array}$ \\
\hline $\begin{array}{l}\text { MDR3 disease } \\
\text { Intrahepatic cholestasis of pregnancy } \\
\text { (ICP) }\end{array}$ & $\begin{array}{l}7 q 21 \\
18 q 21-22,2 q 24,7 q 21\end{array}$ & $\begin{array}{l}\text { MDR3 } \\
\text { ATP8B1 } \\
\text { ABCB11 } \\
\text { MDR3 }\end{array}$ & $\begin{array}{l}\text { PFIC3: extensive bile duct proliferation and fibrosis } \\
\text { Pruritus during third trimester of pregnancy, resolves } \\
\text { after delivery }\end{array}$ \\
\hline \multicolumn{4}{|l|}{ Other familial intrahepatic cholestasis syndromes } \\
\hline $\begin{array}{l}\text { ARC syndrome } \\
\text { Lymphoedema-cholestasis syndrome (LCS)/ } \\
\text { Aagenaes syndrome }\end{array}$ & $\begin{array}{l}15 q 26.1 \\
15 q\end{array}$ & $\begin{array}{l}\text { VSP33B } \\
?\end{array}$ & $\begin{array}{l}\text { Arthrogryposis, renal tubular dysfunction, and cholestasis } \\
\text { Neonatal intrahepatic cholestasis and lymphoedema }\end{array}$ \\
\hline $\begin{array}{l}\text { North American Indian childhood } \\
\text { cirrhosis (NAICC) }\end{array}$ & $16 q 22$ & Cirhin & Neonatal jaundice, biliary cirrhosis \\
\hline
\end{tabular}

acid intermediates di- and trihydroxycholestanoic acid (DHCA and THCA) and present with adult-onset sensory motor neuropathy, but liver function appeared normal in these patients. Interestingly, two brothers are described with THCA syndrome (OMIM 214950); these patients only accumulate THCA and present with cholestasis and obstructive jaundice. ${ }^{22} \mathrm{~A}$ disease locus has not yet been identified.

Finally, loss of D-bifunctional protein activity (fig 3) is associated with the accumulation of C27 bile acid intermediates and pristanic acid. Patients present with hepatomegaly, developmental defects, hypotonia, and seizures. All patients manifest the neurological deficiencies but only some patients have symptoms of liver failure, ${ }^{23}$ probably due to excretion of $\mathrm{C} 27$ bile acid intermediates into bile. ${ }^{24-26}$ Effective therapy for D-bifunctional protein deficiency has not yet been reported.

\section{Common denominators of bile acid biosynthesis defects}

In general, bile acid synthesis defects that affect early biosynthetic steps cause neonatal cholestasis because bile acid intermediates accumulate in the liver. These disorders can generally be treated with oral bile acid therapy. It is hypothesised that bile acid therapy causes suppression of cholesterol $7 \alpha$-hydroxylase preventing further synthesis of cholestatic intermediates (see "Regulation of bile acid homeostasis" section below). One exception is CYP7Bl deficiency, with concomitantly reduced CYP7Al activity and expression, probably because of feedback inhibition of CYP7Al by C-27 hydroxylated cholesterol. This exception could be explained by absence of feedback regulation of bile acids on CYP27A, which is responsible for the first step in bile acid synthesis via the acidic pathway, leading to further accumulation of C-27 hydroxylated cholesterol.

Why do some bile acid synthesis disorders not manifest with liver disease but with neuropathology? AMACR and
D-bifunctional protein are both localised in peroxisomes and both cause neurological defects but liver disease only sometimes. It is thought that the bile acid intermediates that are substrates for these enzymes can function as bile acids. ${ }^{24}$ Both enzymes are not only involved in bile acid synthesis but also act on branched chain fatty acids such as pristanic acid. This explains the accumulation of pristanic acid in both disorders. Pristanic acid, which is neurotoxic, accumulates in the circulation and causes the progressive neuropathy in these patients. A similar phenotype of progressive peripheral neuropathy is characteristic for peroxisome biogenesis disorders such as Refsum disease and Zellweger syndrome. In such generalised peroxisomal disorders, these enzymes are not functional; pristanic acid accumulation is thought to contribute to the neurologic problems in these disorders. ${ }^{27}$

Hyperlipidaemia is observed in some of the biosynthesis disorders. The relationship between defective bile acid synthesis and hyperlipidaemia has long been recognised, but its mechanism is poorly understood. It was suggested that bile acids have an effect on the synthesis of VLDL triglycerides, but there is also evidence that the reduced bile acid pool causes a decrease in the activity of the nuclear hormone receptor FXR (farnesoid $X$ receptor) and a corresponding decline in the expression of apolipoprotein C-II which normally induces lipoprotein lipase activity. ${ }^{328} 29$

The different bile acid biosynthesis defects can easily be distinguished from each other and from bile salt transport defects by mass spectrometry analysis of blood and urine; all have a characteristic pattern of accumulating bile acid intermediates. In the past, mass spectrometry analysis has proven to be a powerful technique for elucidating this class of cholestasis disorders, even before their genetic basis was known. Future studies should address whether mass spectrometry analysis of blood, urine, and bile samples could also distinguish between BSEP and FICl disease (see below), 
because genetic testing currently remains the only strategy to accurately discriminate between these conditions.

\section{BILE ACID SYNTHESIS/TIGHT JUNCTION DEFECT Familial hypercholanaemia (FHCA)}

FHCA is a recently resolved genetic defect, which was diagnosed in 12 families of Old Order Amish descent in Lancaster County in the USA. ${ }^{30}$ Patients manifest fat malabsorption, vitamin $\mathrm{K}$ deficiency, and rickets, indicating a shortage of bile salts in the intestine. Serum bile salt concentrations were usually elevated and cholestasis and chronic hepatitis were sometimes observed. Symptoms could often be reversed by UDCA treatment. A whole genome screen in these families revealed a chromosomal region (9q12-9q13) shared identically by descent in eight FHCA patients. This region contained the candidate gene TJP2. Genomic sequencing of this gene identified a homozygous valine to alanine substitution (V48A) in these eight patients. As three unaffected siblings were also homozygous for this mutation, penetrance of FHCA was incomplete.

Tight junction protein 2 (TJP2) belongs to a family of membrane-associated guanylate cyclase homologues that are involved in the organisation of tight junctions. ${ }^{31}{ }^{32}$ In the hepatocytes, tight junctions have an important role in separating bile from plasma and the canalicular membrane domain from the sinusoidal membrane domain. TJP2 is presumed to affect tight junction structure by binding to claudins and occludin. Carlton et $a l^{30}$ proposed that in patients with the V48A mutation in TJP2, bile salts enter the bile but subsequently leak into plasma through dysfunctional tight junctions, resulting in high serum bile salt concentrations.

In five patients with FHCA the V48A mutation in TJP2 could not be detected. Carlton et $a l^{30}$ discovered a second FHCA locus at 9q22-9q23, which contains the candidate gene $B A A T$ (bile acid CoA:amino acid $N$-acyltransferase), the key enzyme in conjugation of bile acids with glycine or taurine (fig 3 and table 1). Sequencing revealed a methionine to valine substitution (M76V) in BAAT in four individuals who did not harbour the V48A mutation in TJP2. Unconjugated bile acids cannot be secreted into bile by the bile salt export pump (BSEP). ${ }^{33}$ Thus, unconjugated bile acids accumulated in the livers of these patients, with concomitantly reduced concentrations in bile and intestine. Strikingly, five of the eight individuals with the homozygous V48A mutation in TJP2 additionally presented with a heterozygous BAAT mutation and, conversely, one patient with a homozygous M76V mutation in BAAT also had a heterozygous V48A mutation in TJP2. In one patient with FHCA, mutations were not detected in TJP or in BAAT nor was this patient homozygous at either region at chromosome 9. Therefore, a third locus for FHCA probably exists. Interestingly in this respect, recessive mutations in microsomal epoxide hydrolase $(m E H)$, which plays a central role in carcinogen metabolism but is also able to mediate sodium-dependent uptake of bile acids into hepatocytes, are also associated with hypercholanaemia. ${ }^{34}$

Carlton et $a l^{30}$ speculate that manifestation of FHCA associated with homozygous TJP2 mutations requires a concomitant heterozygous mutation in a second locus, such as $B A A T$, or the third locus postulated to be associated with FHCA. The population frequency of the TJP2 V48A mutation is unexpectedly high (7\%) for the number of FHCA patients detected with a homozygous TJP2 mutation, indicating that this disease has an oligogenic mode of inheritance. Both $B A A T$ and TJP2 may represent important genetic modifiers of disease severity. Further studies should address whether there are differences in clinical and biochemical presentation in FHCA patients with distinct genetic backgrounds.

\section{TRANSPORTER DEFECTS AFFECTING BILE FORMATION}

After biosynthesis of bile acids or reuptake of bile salts from blood into hepatocytes, conjugated bile acids are actively transported into the bile canaliculus, where they are the predominant components of bile. Bile formation in bile canaliculi is an osmotic process that largely depends on secretion of various compounds by ATP-dependent transporters in the canalicular membrane of the hepatocytes. In this way bile salts, and also cholesterol, bilirubin, bicarbonate, glutathione, heavy metals, various drugs, toxins, and phospholipids are secreted into bile. The protein pumps responsible for the transport of these compounds are ATPbinding cassette $(\mathrm{ABC})$ transporters or transporters that belong to the P-type ATPase superfamily. Several of these transporter genes are associated with familial cholestasis syndromes or other hereditary disorders in man.

Progressive familial intrahepatic cholestasis (PFIC) and benign recurrent intrahepatic cholestasis (BRIC) are two long recognised autosomal recessive hereditary cholestasis disorders characterised by a defect in bile secretion. However, when these disorders were first described it was not known that PFIC and BRIC displayed genetic heterogeneity. Currently, PFIC is known to be associated with mutations in ATP8B1 (PFIC1), ABCB11 (PFIC2), and MDR3 (PFIC3), while BRIC is associated with mutations in ATP8BI (BRIC1) and $A B C B 11$ (BRIC2). A subtype of BRIC with autosomal dominant inheritance is also described, but the gene mutated in this defect has not yet been identified. ${ }^{35}$

\section{FICl disease}

FICl disease is defined by genetic criteria: all patients have mutations in ATP8B1. However, the disorder comprises at least three previously described clinical entities: progressive familial intrahepatic cholestasis type l (PFIC1), benign recurrent intrahepatic cholestasis type l (BRICl), and Greenland familial cholestasis (GFC).

PFIC was first reported in an Amish family who were all descendants of a Jacob Byler, hence the former name Byler disease. $^{36}$ Seven patients of this family suffered the same symptoms: steatorrhoea, diarrhoea, jaundice, hepatosplenomegaly, and failure to thrive. From the Byler pedigree it was deduced that the disorder followed autosomal recessive inheritance. Because patients presented with very low biliary bile salts, but high serum levels of bile salts, a bile acid biosynthesis defect was ruled out. Therefore, these patients were thought to have a defect in bile salt transport.

Subsequently, homozygosity mapping identified a locus for PFIC at chromosome 18q21-q22, ${ }^{37}$ the same locus previously attributed to BRIC. ${ }^{38}$ BRIC was first described in 1959 by Summerskill and Walshe ${ }^{39}$ and manifests with similar symptoms although with episodic attacks of cholestasis. Between attacks the patients are symptom-free and the progressive liver damage seen at an early age in PFIC is not seen in BRIC. Further studies revealed that both disorders were associated with mutations in the same gene, ATP8B1, which encodes FICl, and currently these disorders are termed PFICl and BRICl. One other syndrome of intrahepatic cholestasis in childhood, Greenland familial cholestasis (GFC), was described in 16 Inuit children from Greenland. ${ }^{40}$ The patients presented shortly after birth with jaundice and pruritus. Homozygosity mapping revealed homozygosity for a conserved microsatellite haplotype on chromosome 18, containing ATP8B1. ${ }^{41}$ In 2000, Klomp et a ${ }^{42}$ identified a homozygous missense mutation (D554N) in the ATP8BI gene as the cause of GFC.

All three clinical entities present with and are defined by normal or slightly elevated gamma-glutamyl transpeptidase (GGT) activity in serum. GGT is normally bound to the 
canalicular membrane by a glycosyl phosphatidyl inositol (GPI) anchor, but when excessive amounts of bile salts are present in the canaliculus, the detergent activity liberates GGT, which is usually seen in obstructive cholestasis. In FICl disease, however, it is thought that the reduced concentration of bile salts in bile preserves GGT localisation at the canalicular membrane, hence the normal GGT activity in serum.

Mutation analysis has revealed 39 different mutations in $A T P 8 B 1$ in PFICl patients and 19 in BRICl patients. ${ }^{38-47}$ The ATP8B1 I661T mutation is the most common mutation in FICl disease; it was detected in approximately $75 \%$ of BRIC 1 patients but was associated with a remarkable variability in clinical presentation. ${ }^{44}$ Compound heterozygosity for I661T and other different mutations can lead to PFICl. Homozygosity for I661T is associated with recurrent phenotypes and even with a symptom-free life, ${ }^{44}$ indicating incomplete penetrance. The differences in phenotypes of these patients with the same homozygous mutation suggest that environmental factors and/or modifier genes play a role in the clinical expression of FICl disease. Candidates for modifier genes of FICl disease could be TJP2 and BAAT (described above). Interestingly, patients from the Faeroe Islands with the homozygous I661T mutation have similar genetic makeup, but this group of patients still shows marked heterogeneity in disease phenotype. ${ }^{47}$

It was postulated that BRIC 1 and PFIC 1 represent two ends of a phenotypic spectrum, because both are caused by mutations in the same gene. An intermediate form between BRICl and PFICl was described by Van Ooteghem et al ${ }^{48}$ in two BRICl patients with a splice site mutation resulting in skipping of exon 24. These patients presented with recurrent cholestatic bouts initially but developed progressive cholestasis later in life. A difference in the severity of mutations is likely to be linked to this phenotypic continuum. Consistent with this notion, $63 \%$ of the ATP8BI mutations identified in BRICl patients were missense mutations, whereas only $41 \%$ of mutations associated with PFICl are missense mutations. PFICl patients more often have nonsense and frame shift mutations than BRICl patients; these mutations likely alter protein structure and/or function severely. ${ }^{44}$ Residual activity of FICl protein could be the explanation for the relative mild phenotypes observed in BRICl patients. Future functional studies should systematically address the effects of ATP8BI mutations associated with mild and severe disease.

FICl is expressed at the apical membranes of different epithelial cells: at the apical membranes of enterocytes from the proximal to the distal intestine, of cells lining the gastric pits, of pancreatic acinar cells, and of cholangiocytes and hepatocytes. ${ }^{49-51}$ Strikingly, the expression in hepatocytes is low compared to that in some other tissues. Pancreatitis and diarrhoea are commonly observed in FICl disease patients and do not resolve after liver transplantation. ${ }^{46} 4752$ These symptoms are probably explained by the absence of FICl function in pancreas and intestine in these patients. Mice with an engineered mutation in Atp8bl, the G308V mutation that was commonly detected in patients of Amish descent, displayed no cholestatic phenotype and unimpaired biliary secretion, even upon bile salt feeding, but these mice did present with serum bile salt accumulation, weight loss, jaundice, and hepatomegaly, suggesting that there is a defect in the regulation of resorption of bile acids in the cholangiocytes or enterocytes. Furthermore, Atp $8 b 1^{G 308 V /}$ G308V mice counteract bile salt accumulation by enhanced rehydroxylation of excess bile salts, indicating an important difference between mice and humans. ${ }^{53}$

During immediate postnatal development, FICl expression is hardly detectable in the intestinal tissue of newborn mice but is specifically induced at 3 weeks of postnatal life. In contrast, FICl is already expressed in liver, pancreas, and stomach before weaning and is not further induced during postnatal development. ${ }^{49}$

It is presently unclear how all these observations fit into a working model of the function of FICl and how impairment of FICl activity causes intrahepatic cholestasis. The primary biochemical function of FICl is not yet known. However, it belongs to the P4 P-type ATPase subfamily and initial functional studies have suggested that this subfamily may have conserved functions in the transport of aminophospholipids from the outer leaflet to the inner leaflet of plasma membranes, ${ }^{54-56}$ but this has not been unequivocally demonstrated. ${ }^{57}$ Indeed, Ujhazy et $a l^{51}$ were able to demonstrate aminophospholipid translocase activity in canalicular liver membrane preparations which contained FICl protein. Transfection of CHOKl cells with ATP8BI cDNA resulted in the appearance of FICl in membrane preparations and energy-dependent translocation of a fluorescent analogue of phosphatidylserine, providing indirect evidence that FICl may actually represent an aminophospholipid transporter. ${ }^{51}$ How this proposed function is related to bile salt transport is unclear.

As an aminophospholipid translocase, FICl might have a role in intracellular vesicular transport, thereby regulating proper expression or function of the canalicular transporters such as BSEP. Such a function would be consistent with the localisation of FICl at the canalicular membrane. ${ }^{50}{ }^{51} \mathrm{~A}$ recent preliminary study revealed unremarkable BSEP expression at the canalicular membrane of hepatocytes in PFICl patients, but BSEP function was not addressed. ${ }^{58}$ In addition, the expression of $\mathrm{P}$-glycoproteins at the canalicular membrane was not affected in a PFICl patient. ${ }^{50}$ There are additional hypotheses for the function of FICl; it might be a bile salt transporter for hydrophilic bile salts or could play a role in ion transport, based on the $30 \%$ homology with P-type ATPases that function as $\mathrm{Ca}^{2+}$ transporters. These hypotheses are explained in more detail in van Mil et al ${ }^{59}$; further studies are required to reveal how the biochemical function of FICl is related to bile salt homeostasis.

Recently, Chen et $a^{l^{60}}$ observed that in ileal biopsies from PFICl patients and in Caco2 cells treated with ATP8BI antisense oligonucleotides, $A S B T$ expression was increased, whereas FXR, short heterodimeric partner $(S H P)$, and IBABP showed reduced expression. The authors proposed that loss of FICl expression leads to diminished nuclear translocation of FXR. This hypothesis partly explains the pathophysiology of FICl disease as pathologic alterations in the transcriptional regulation of intestinal and hepatic bile acid transport expression. Cholestasis presumably develops because of both enhanced ileal uptake of bile acids via up-regulation of ASBT and diminished canalicular secretion of bile acids secondary to down-regulation of BSEP. Although this possible explanation of FICl disease pathophysiology is attractive, it raises a novel question as to how FICl expression regulates FXR activity. The observed changes in transporter expression might also be secondary to altered bile acid levels resulting from diminished FICl expression or function.

Mutations in ASBT are associated with primary bile acid malabsorption (PBAM), which manifests with chronic intractable diarrhoea, steatorrhoea, interruption of the enterohepatic circulation, and reduced plasma cholesterol levels. ${ }^{61}$ Both FICl disease and PBAM result in chronic intractable diarrhoea, although there are elevated and diminished levels, respectively, of functional ASBT present, which indicates that the pathogenesis of the diarrhoea is different in these disorders.

\section{BSEP disease}

In 1997, a second locus for PFIC with normal serum GGT activity was mapped to chromosome 2q24 by homozygosity 
mapping and linkage analysis.6. ${ }^{62}$ After locus refinement, mutations were detected in ABCBII (formerly called SPGP and $B S E P),{ }^{63}$ which encodes BSEP, an ABC transporter that was first cloned in rat. In vitro studies revealed that it functions as a bile salt transporter and is expressed solely at the canalicular membranes of hepatocytes. ${ }^{33}{ }^{64-66}$

The knockout of $A b c b 11$ in mice resulted in intrahepatic cholestasis but with significantly less severity than found in human patients with mutations in ABCB11 (PFIC2 patients). ${ }^{67}$ Biliary cholate excretion was reduced to $6 \%$ of that of wildtype mice, but there was excretion of tetrahydroxylated bile salts, which were not detected in healthy littermates. Hence, the bile salt output was $30 \%$ of that of wildtype mice, whereas bile salt output in PFIC2 patients is almost absent. These results suggest that hydroxylation and an alternative canalicular transport mechanism can compensate for the absence of $A b c b l l$ in mice and this may protect the mutant mice from liver damage. ${ }^{67}$ Crossing these mice with several other mouse models might reveal the nature of this alternative canalicular transport mechanism.

A large number of different mutations have been described in patients with PFIC2. ${ }^{63}{ }^{68}$ Two mutations, E297G and $\mathrm{D} 482 \mathrm{G}$, are commonly detected and have been described in 25 and 16 families, respectively; at least one of these two mutations is present in $30 \%$ of PFIC2 patients of European descent. ${ }^{69}$ Functional studies revealed that in the case of the E297G mutation, almost all bile salt transport activity was abolished, probably because the mutation caused misfolding of the newly synthesised protein. ${ }^{70}$ For the D482G mutation, functional studies revealed conflicting results; Wang et al reported that a mutated rat BSEP was expressed normally at the apical membranes of MDCK cells but had diminished activity, ${ }^{70}$ but Plass et al ${ }^{71}$ reported that mouse BSEP with the D482G mutation was glycosylated inefficiently and was therefore retained intracellularly. The $\Delta \mathrm{F} 508$ mutation in the ABC transporter CFTR also leads to inefficient glycosylation of the mutant protein, and the processing and stability of mutant BSEP as well as CFTR were shown to be temperature sensitive..$^{62} 7273$ These studies are important in elucidating the effects of the mutations and in providing new therapeutic strategies.

As in PFIC1, PFIC2 manifests with severe intrahepatic cholestasis in infancy and progresses to end-stage liver disease and death in childhood, unless a liver transplantation, a partial biliary diversion, or an ileal exclusion is performed. There are some variable differences between PFIC1 and PFIC2: extrahepatic features have been described exclusively in PFICl patients but not in PFIC2 patients. Also, PFIC2 often presents with non-specific giant cell hepatitis, whereas in PFICl, the cholestatic liver disease is typically more bland. Despite these variable differences, it is currently only possible to accurately distinguish between PFICl and PFIC2 by genetic testing.

Recent genetic evidence implies a third locus for autosomal recessive PFIC, because 10 families were inconsistent with linkage to either $A B C B 11$ or $A T P 8 B 1^{74}$ and no mutations in either $A B C B 11$ or $A T P 8 B 1$ could be detected in several PFIC patients. ${ }^{44}$ In this last study, $83 \%$ of BRIC patients did not harbour mutations in ATP8B1, strongly suggesting that there is at least one additional locus underlying autosomal recessive BRIC.

Recently, it was discovered that 11 BRIC patients from eight different families harboured mutations in $A B C B 11$; these individuals are currently denoted as BRIC2 patients. ${ }^{75}$ None of these BRIC2 patients manifest with extrahepatic features, but seven out of 11 presented with cholelithiasis. It was speculated that supersaturation of cholesterol in bile occurs due to diminished bile salt secretion, secondary to impaired BSEP function, ${ }^{76}$ and that this may account for the high incidence of gallstone formation. Interestingly, $A b c b 11$ is one of two candidate genes of the Lithl locus, which is associated with increased risk of gallstone formation in inbred mice. Three BRIC2 patients manifest with progressive cholestasis in the third or fourth decade of life, as was also described for two BRICl patients. Therefore, it was proposed that $A B C B 11$ disease ranges along a phenotypic continuum, as was described previously for ATP8B1 disease. ${ }^{59}$ The E297G mutation that was commonly detected in PFIC2, was also observed in homozygous form in two BRIC2 families, indicating that other genetic and environmental factors play a role in the phenotypic expression of $A B C B 11$ disease. As in $A T P 8 B 1$ disease, there seems to be a correlation between the predicted effects of mutations and the severity of the phenotype. In this same study, 12 BRIC patients did not harbour mutations in either $A T P 8 B 1$ or $A B C B 11$, providing additional evidence for a third locus for autosomal recessive BRIC and PFIC with low serum GGT activity.

\section{MDR3 disease}

Individuals with MDR3 disease are called PFIC3 patients. PFIC3 is quite different from the other PFIC subtypes, because serum GGT activity is usually elevated in these patients and liver histology shows extensive bile duct proliferation and fibrosis. ${ }^{77-79}$ The age of onset ranges from 1 month to 20.5 years of age and the most prominent features are portal hypertension, hepatosplenomegaly, jaundice, pruritus, and liver failure later in life.

The genetic background of PFIC3 was elucidated after mice with a disruption in the $M d r 2$ gene, the murine orthologue of human $M D R 3$, were found to develop hepatocyte necrosis, dilated canaliculi, cholangiopathy represented by portal tract inflammation, severe ductular proliferation in the first 3 months of life, and hepatocellular carcinoma. ${ }^{80}$

The bile of Mdr2 knockout mice and PFIC3 patients is almost devoid of phosphatidylcholine, whereas bile salt secretion is normal. Normally, phosphatidylcholine is the predominant phospholipid in bile. Bile salts secreted into the bile canaliculi induce the extraction of phospholipids from the exoplasmic leaflet of the canalicular membrane. In the biliary tree phospholipids are of crucial importance in protecting the cellular membranes against the high concentrations of bile salts by the formation of mixed micelles. Ruetz and Gros ${ }^{81}$ discovered that Mdr2 translocates phosphatidylcholine from the inner to the outer plasma membrane leaflet. The phenotypic and biochemical similarities between PFIC3 patients and $M d r 2^{-/-}$mice led Hadchouel, Oude Elferick, and coworkers ${ }^{77-79}$ to investigate whether mutations in MDR3 underlie PFIC3. This revealed 17 different mutations in MDR3 (at chromosome 7q21) in 22 PFIC3 patients: 11 missense mutations and six mutations that were predicted to result in a truncated protein. ${ }^{77-79}$ The truncated MDR3 proteins could not be detected in the livers of these patients by immunochemical methodology and almost no biliary phospholipids were present in samples obtained from patients affected with such MDR3 mutations, whereas residual expression of $M D R 3$ was observed concomitantly with low but detectable levels of biliary phospholipids in some patients with missense mutations in MDR3. Children with an MDR3 missense mutation have relatively mild disease, with late onset and a slow progression. Missense mutations are likely associated with residual transport activity and treatment with UDCA was beneficial in most patients with missense mutations but not in patients with truncating $M D R 3$ mutations. It was hypothesised that, despite the reduced amounts of phospholipids in bile, partial replacement of endogenous hepatoxic bile acids by the hydrophilic UDCA can realise a reduction of bile salt toxicity. ${ }^{82}$ In conclusion, MDR3 disease can be associated 
with mild and severe liver disease, as we described above for FICl and BSEP disease.

\section{Intrahepatic cholestasis of pregnancy (ICP)}

Intrahepatic cholestasis of pregnancy (ICP) is a reversible form of cholestasis that may develop in the third trimester of pregnancy and persists until delivery. The main symptoms are pruritus and to a lesser extent, jaundice. ${ }^{83} 84$ Serum bile salt levels are increased. The prognosis is good for the mother, but ICP can be associated with increased incidence of fetal distress, premature birth, and stillbirth. ${ }^{85}$ Oestrogen and progesterone levels probably have important roles in the pathogenesis of ICP because the disease starts in the last trimester of pregnancy, when the hormone concentrations are high, and resolves 1 or 2 days after delivery, when levels of placenta-derived hormones return to normal..$^{86}$

In ethinyloestradiol-induced cholestasis in rats, the expression of basolateral bile acid transport proteins (NTCP and different OATPs) is inhibited at the transcriptional level, ${ }^{88} 89$ which could explain the etiology of cholestasis in ICP.

Besides hormonal factors, genetic factors play a role in ICP. A higher incidence of ICP has been observed in mothers of patients with PFIC1, PFIC3, or BRIC1, ${ }^{36} 9091$ indicating that heterozygous mutations in genes involved in bile formation predispose to ICP, thereby underscoring the contribution of genetic factors to the development of ICP. More frequently, ICP occurs in women with no known family history of PFIC. In some of these patients heterozygous mutations were detected in MDR3. ${ }^{92}{ }^{93}$ Savander et al ${ }^{94}$ genotyped 16 individuals from two Finnish ICP families for markers flanking $A B C B 11, A T P 8 B 1$, and $M D R 3$, but linkage to any of these genes was excluded, indicating that further genetic heterogeneity in ICP is expected. Known genes involved in the regulation of bile acid metabolism are good candidates for factors predisposing to ICP. Finally, environmental factors might also increase the risk for ICP. This is indicated by the fact that ICP recurs in less than $70 \%$ of pregnancies in multiparous women and by the decline in ICP prevalence rates in Chile over the last decade. ${ }^{95}$ Furthermore, the incidence of ICP is reported to be higher in winter than in summer. ${ }^{96}$

During ICP, there is an increased flux of bile salts from the mother to the fetus and it is hypothesized that the placental transfer capacity for bile salts is reduced. This might result in decreased fetal elimination and retention of toxic bile salts by the fetus, which may explain the higher risk of premature birth and stillbirth in these pregnancies. ${ }^{97}{ }^{98}$ UDCA has been shown to be beneficial in ICP mothers and the incidence of fetal loss decreases. ${ }^{99}$ Furthermore, because stillbirths occur late in pregnancy, labour is induced in these women before term.

\section{OTHER FAMILIAL INTRAHEPATIC CHOLESTASIS SYNDROMES \\ ARC syndrome/VPS33B deficiency}

ARC syndrome refers to an autosomal recessive association between arthrogryposis, renal tubular dysfunction, and cholestasis. It has become apparent that there is notable clinical variability, even within the same family. Cases may even be undiagnosed as not all patients present with these three cardinal features. ${ }^{100}{ }^{101}$ Additional symptoms have been reported in some patients, including diarrhoea, cerebral malformation, nerve deafness, nephrogenic diabetes insipidus, and failure to thrive. Most patients die by the age of 7 months, but those who exceed this age have shown severe developmental delay. ${ }^{102}$

The GGT activity in serum in these ARC patients with neonatal cholestasis is low, indicative of decreased amounts or absence of biliary bile salts, and suggestive of a defect in bile salt transport. Because of the multiplexity of the ARC syndrome, a general membrane transport defect was expected. ${ }^{103}$ Since it is expressed in multiple tissues, including brain, liver, kidney, intestine, and skeletal muscle, ATP8BI was suspected as a candidate gene mutated in this disorder, but mutations in ATP8B1 were excluded by Gissen et al. ${ }^{104}$

Recently, it was demonstrated that recessive mutations in VPS33B at chromosome 15q26.1 cause ARC syndrome. ${ }^{105}$ Nine different mutations have been characterised, the majority leading to truncated VPS33B proteins. VPS33B encodes a homologue of the yeast $S$ cerevisiae class $C$ vacuolar protein sorting 33 gene (Vps33) which is important in the regulation of the fusion of intracellular vesicles with the plasma membrane. VPS33B interacts with members of the syntaxin family of t-SNAREs, thereby probably influencing vesicle SNARE to target SNARE complex assembly, an essential step in determining the specificity of heterotypic membrane docking and fusion. The clinical features of ARC syndrome are consistent with abnormal intracellular protein trafficking and defective membrane fusion mechanisms. The neonatal cholestasis with low GGT activity observed in these patients is probably caused by the absence of bile salt transport proteins at the canalicular membranes of these patients. Consistent with this observation, the polarised localisation of a canalicular marker protein, carcinoembryonic antigen (CEA), was markedly disturbed in liver biopsies of ARC patients. ${ }^{105}$

\section{Lymphoedema-cholestasis syndrome (LCS) or Aagenaes syndrome}

Patients with LCS (lymphoedema-cholestasis syndrome), also called Aagenaes syndrome, suffer from severe neonatal intrahepatic cholestasis and develop lymphoedema in their youth. In most patients, the cholestasis lessens during early childhood and becomes episodic, as in BRIC. A few patients, however, manifest with cirrhosis and death in early childhood, or develop cirrhosis as adults. The lymphoedema, which can start at birth or in early childhood, becomes chronic and severe, mainly affecting the lower extremities but also the hands, scrotum, and periorbital soft tissues.

Aagenaes first described LCS in patients in an isolated population in the south west of Norway. To date, there have been many published cases: most are Norwegian but some are of other origin. ${ }^{106}{ }^{107}$ Bull et al mapped a locus for LCS to chromosome 15q in Norwegian patients, ${ }^{107}$ but the gene has not yet been identified. Interestingly, the locus for LCS reported by Bull et al contains VPS33B, which is mutated in ARC syndrome, and both disorders manifest with developmental defects. Sequencing of VPS33B in LCS patients is therefore warranted. In a consanguineous Serbian Romani LCS family no linkage was detected at chromosome 15q, suggesting that locus heterogeneity exists for LCS. ${ }^{108}$

It is not know whether the normal GGT cholestasis in this syndrome is a direct or a secondary feature of the LCS gene defect. Cholestasis might develop due to abnormal function of the lymphatic system or both lymphatic vessels and bile ducts might develop abnormally. ${ }^{109} 110$ Perhaps the livers of LCS patients are able to compensate for the gene defect in LCS later in life. ${ }^{107}$

\section{North American Indian childhood cirrhosis/Cirhin deficiency (NAICC)}

North American Indian childhood cirrhosis (NAICC) is a rapidly evolving form of familial cholestasis with autosomal recessive inheritance found in Ojibway-Cree children from north western Quebec in Canada. ${ }^{111}{ }^{112}$ The disease manifests with transient neonatal jaundice, which progresses to biliary cirrhosis requiring hepatic transplantation in childhood or young adulthood. Histological samples show early bile duct proliferation and rapid development of portal fibrosis and biliary cirrhosis, suggesting involvement of bile ducts rather 
than bile canaliculi. A missense mutation in Cirhin at chromosome 16q22 has been detected in these patients. The secondary structure predicts that this protein contains $10 \mathrm{WD}$ repeats (also known as WD40 or beta-transducin repeats), which are short motifs of approximately 40 amino acids, often terminating in a Trp-Asp (WD) dipeptide. WD repeats are implicated in the organisation of proteins into complexes and are thus involved in many processes such as signal transduction, vesicular trafficking, cytoskeletal assembly, and transcription initiation complex assembly. ${ }^{113-115}$ The elucidation of the function of Cirhin requires further studies. Furthermore, since all patients with Cirhin deficiency currently are from one isolated population, the clinical presentation of NAICC may expand when other unrelated patients with Cirhin deficiency are identified.

\section{REGULATION OF BILE ACID HOMEOSTASIS}

Because of the intrinsic toxicity of bile acids, bile acid synthesis and transport must be tightly regulated. It is now apparent that members of the nuclear hormone receptor family of lipid-activated transcription factors are key regulators of these physiological processes. Nuclear hormone receptors, after sensing inappropriate oxysterol and bile acid levels, are transcription factors that initiate the genetic transactivation of DNA response elements in promoter regions of target genes to modulate the synthesis of bile acids and their enterohepatic circulation. The four key nuclear hormone receptors that regulate bile acid homeostasis are FXR, VDR, PXR/SXR, and LXR, although others have been described (for reviews, see Betard et al, ${ }^{113}$ Chagnon et al, ${ }^{114}$ Smith et al, ${ }^{115}$ Chawla et al, ${ }^{116}$ Goodwin et al, ${ }^{117}$ and Redinger et $\mathrm{l}^{118}$ ). FXR, PXR/SXR, and VDR bind bile acids and are therefore sensors of excessive amounts of bile acids, whereas LXR is a cholesterol sensor and binds oxysterols. These nuclear hormone receptors act as heterodimers; RXR, the retinoid receptor, is an obligatory partner in this heterodimer.

When bile acid levels increase in hepatocytes, the farnesoid $\mathrm{X}$ receptor (FXR) binds bile acids, which then activates transcription of short heterodimeric partner (SHP). SHP inhibits transcription of $L R H 1$, the liver receptor homologue 1, which normally transactivates CYP7Al and CYP7B1. Consequently, bile acid synthesis is inhibited (fig 4)..$^{10}$ SHP is also responsible for the inhibition of the transcription of NTCP, encoding the principal importer of bile salts at the basolateral membrane; this leads to a reduction of bile salt absorption into hepatocytes (fig 4). ${ }^{119-121}$ On the other hand, FXR induces transcription of BSEP resulting in enhanced secretion of excessive bile salts into bile (fig 4). ${ }^{122}$ Hence, FXR functions as a bile acid sensor to maintain low bile acid concentrations in hepatocytes. In the intestine, FXR facilitates bile salt secretion into the portal circulation through induction of the ileal bile acid binding protein $(I B A B P)$ gene (fig 4). ${ }^{123}$ Mice lacking the nuclear bile acid receptor Fxr developed normally but are distinguished from wildtype mice by elevated serum and hepatic bile acid, cholesterol, and triglyceride levels. $\mathrm{Fxr}^{-1-}$ mice also had reduced bile acid pools and reduced fecal bile salt excretion due to decreased expression of BSEP. These data demonstrate that FXR is critical for bile acid and lipid homeostasis. ${ }^{124}$

The pregnane $X$ receptor (PXR) can be activated by the toxic bile acid LCA. PXR inhibits transcription of CYP7A $I^{125}$ but also stimulates transcription of CYP $3 A 4$, a cytochrome P450 enzyme that detoxifies secondary bile acids by monooxygenation leading to formation of more hydrophilic bile acids (fig 4). The vitamin D nuclear receptor (VDR) binds vitamin D but also LCA at low concentrations, which also results in induction of CYP $3 A 4$ expression in the enterocytes and cholangiocytes, which explains how the enteric system and the biliary epithelium could protect themselves from the harmful effects of LCA (fig 4). ${ }^{126}{ }^{127}$ This may be the secondary defence protecting the liver against the accumulation of highly toxic bile acids. ${ }^{128}$ When cholesterol levels increase in hepatocytes, oxysterols activate the liver X receptor $\alpha$ (LXR $\alpha$ ) to induce CYP7Al to convert excess cholesterol into bile acids. ${ }^{129}$ This provides a feed-forward mechanism to primarily regulate cellular cholesterol levels rather than bile acid levels.

Bile salt homeostasis is also regulated at the posttranslational level. Oestradiol-17 $\beta$-D-glucuronide has been shown to induce an acute and completely reversible cholestasis in the rat. The mechanism of pathogenesis of cholestasis is explained by the induction of endocytic internalisation of both Bsep and Mrp2 by oestradiol-17 $\beta$-D-glucuronide, thereby rapidly reducing the number of canalicular transporters. Mrp2 is an ABC type transport protein that secretes glutathione but also the lithogenic sulfated and glucuronated bile salts across the canalicular membranes of hepatocytes. ${ }^{130131}$ Bile duct ligation in the rat, a well known experimental model of cholestasis, also resulted in decreased Mrp2 protein at the canalicular membrane accompanied by intracellular localisation of the protein in pericanalicular vesicular structures. ${ }^{130-132}$ In any case, these events provide a rapid way to regulate the cell surface expression of bile salt transporters based on cellular demand and further studies of the molecular mechanisms governing this posttranslational regulation may permit the development of novel therapeutic approaches to prevent or ameliorate the clinical symptoms of cholestasis.

\section{CONCLUDING REMARKS AND FUTURE PERSPECTIVES}

Identification of genes involved in familial intrahepatic cholestasis has proven to be an important strategy to unravel the processes of bile acid synthesis and bile salt transport. The complexity of the mechanisms of bile flow clearly suggests that many more genetic abnormalities have yet to be identified. Consistent with this hypothesis, numerous unexplained familial cholestasis syndromes are known and the affected genes are likely to have a role in bile flow (for a list of these syndromes see Jansen $e t a^{133}$ ). Identification of the genes involved in these syndromes will further enhance our insight into bile formation and cholestasis. Polymorphisms in these genes may cause an individual's response to changes in bile acid homeostasis to vary and may be genetic modifiers of disease severity. Genes involved in the regulation of bile acid homeostasis are candidate genes for idiopathic hereditary cholestasis syndromes.

Mass spectrometry analysis remains an important tool for future studies to elucidate enzyme defects in bile acid synthesis and further studies should reveal whether this application can also distinguish between specific transport defects. Microarray and proteomic approaches that compare RNA or protein expression patterns in livers from patients or mouse models with different forms of familial cholestasis, could identify new players in bile flow but may also be tools to recognise specific gene defects. Such approaches will also define common pathophysiological pathways responsible for liver damage in different forms of intrahepatic cholestasis.

Phenotype-genotype correlation studies are possible for those disorders in which many different mutations have been identified. In FICl disease, BSEP disease, and MDR3 disease, a correlation between the types and location of distinct mutations in the affected genes and the severity of the patient's phenotype has been observed. These observations need to be complemented by additional functional studies that allow determination of the impact of distinct mutations on protein localisation, expression, and function. Often, missense mutations cause relatively mild symptoms and it 


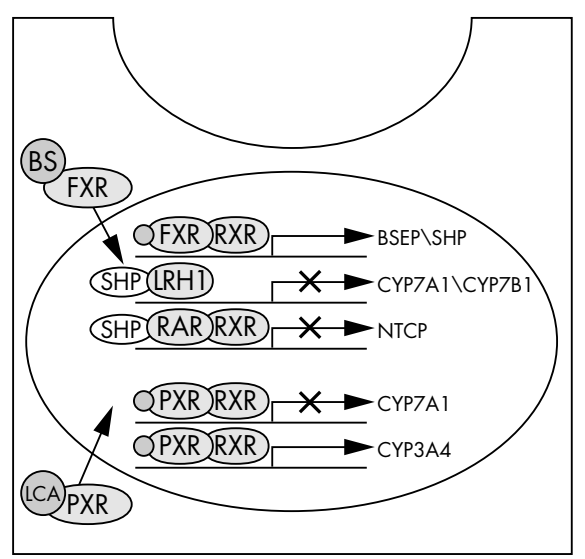

High bile salt concentrations in hepatocyte

Bile salt synthesis
Bile salt secretion
Bile salt absorption
Bile salt detoxification

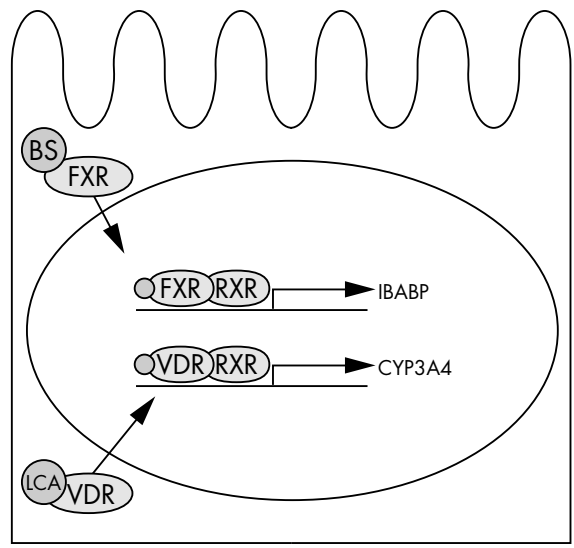

High bile salt concentrations in enterocyte

Bile salt secretion into portal circulation

Bile salt detoxification

Figure 4 Role of nuclear hormone receptors in transcriptional regulation of bile acid synthesis and transport. In response to high concentrations of bile acids, bile acid synthesis and absorption in the hepatocyte are decreased, whereas bile salt secretion and detoxification are increased due to nuclear hormone receptor action. In the enterocyte, detoxification of secondary bile acids is increased and the secretion of bile acids into the portal venous system is eventually enhanced by transcriptional activation of IBABP. See text for further explanation.

is thought that residual activity of the mutated proteins explains this observation. Novel therapeutic approaches for these patients might be found by inducing the expression of the mutated proteins. Recent knowledge concerning the regulation of bile acid homeostasis by nuclear hormone receptors is promising in this respect, because specific agonists and antagonists of nuclear hormone receptors are now being developed. Not only might specific genetic disorders be treatable with such agonists and antagonists, but symptoms of patients with acquired forms of cholestasis might also improve using this approach. UDCA has recently been found to be effective in ameliorating intrahepatic cholestasis in some cases not only because it replaces the toxic endogenous bile acid pool by the less toxic, less hydrophobic bile acid UDCA, but also because it is a ligand for PXR. PXR transactivates CYP3A4, resulting in enhanced detoxification of bile acids. ${ }^{134}$ Other PXR agonists such as rifampicin, often used for treatment of cholestasis, may also enhance CYP3A4 expression. Furthermore, FXR agonist GW4064 has been shown to enhance Bsep expression resulting in increased bile salt export from mouse hepatocytes. ${ }^{135}$ Combined therapy with PXR and FXR agonists holds great promise as a potential remedy for cholestasis symptoms.

Gene defects in bile acid synthesis are often treatable with bile acid supplements. For deficiencies in canalicular export, however, orthotopic liver transplantation or partial external biliary diversion are still the best treatment options. In addition to drug therapy, other remedies have to be explored. Genes that are exclusively expressed in the liver are good candidates for gene therapy: restoration of gene function should confer a selective advantage in bile acid handling to a population of hepatocytes. ${ }^{136}$ However, these approaches to curative therapy may be far away.

\section{ACKNOWLEDGEMENTS}

We thank Ruud Berger for his continuous enthusiastic support and members of our laboratory for helpful discussions.

\section{Authors' affiliations}

S W C van Mil, L W J Klomp, Department of Metabolic and Endocrine Disorders, University Medical Center, Utrecht, The Netherlands R H J Houwen, Department of Pediatric Gastroenterology, University Medical Center, Utrecht, The Netherlands

Our research is supported by grant SW006 from the University Medical Center Utrecht, grant WS 98-12 from the Dutch Digestive Disease Foundation, and by a "high-potential" award from Utrecht University.

Competing interests: none declared

\section{REFERENCES}

1 Alpini G, Glaser SS, Rodgers R, Phinizy JL, Robertson WE, Lasater J, Caligiuri A, Tretjak Z, LeSage GD. Functional expression of the apical Na+dependent bile acid transporter in large but not small rat cholangiocytes. Gastroenterology 1997;113(5):1734-40.

2 Lazaridis KN, Pham L, Tietz P, Marinelli RA, deGroen PC, Levine S, Dawson PA, LaRusso NF. Rat cholangiocytes absorb bile acids at their apical domain via the ileal sodium-dependent bile acid transporter. J Clin Invest 1997; 100(11):2714-21.

3 Russell DW. The enzymes, regulation, and genetics of bile acid synthesis. Annu Rev Biochem 2003;72:137-74.

4 Hofmann AF. The continuing importance of bile acids in liver and intestinal disease. Arch Intern Med 1999;159(22):2647-58.

5 Hofmann AF. Bile acids: the good, the bad, and the ugly. News Physiol Sci 1999;14:24-9.

6 Scholmerich J, Becher MS, Schmidt K, Schubert R, Kremer B, Feldhaus S, Gerok W. Influence of hydroxylation and conjugation of bile salts on their membrane-damaging properties - studies on isolated hepatocytes and lipid membrane vesicles. Hepatology 1984;4(4):661-6.

7 Chiang JY. Bile acid regulation of gene expression: roles of nuclear hormone receptors. Endocr Rev 2002;23(4):443-63.

8 Ishibashi S, Schwarz M, Frykman PK, Herz J, Russell DW. Disruption of cholesterol 7alpha-hydroxylase gene in mice. I. Postnatal lethality reversed by bile acid and vitamin supplementation. J Biol Chem 1996;271(30): 18017-23. 
9 Pullinger CR, Eng C, Salen G, Shefer S, Batta AK, Erickson SK, Verhagen A, Rivera CR, Mulvihill SJ, Malloy MJ, Kane JP. Human cholesterol 7alphahydroxylase (CYP7A1) deficiency has a hypercholesterolemic phenotype. $J$ Clin Invest 2002;110(1):109-17

10 Goodwin B, Watson MA, Kim H, Miao J, Kemper JK, Kliewer SA. Differential regulation of rat and human CYP7A1 by the nuclear oxysterol receptor liver X receptor-alpha. Mol Endocrinol 2003;17(3):386-94.

11 Setchell KD, Schwarz M, O'Connell NC, Lund EG, Davis DL, Lathe R, Thompson HR, Weslie TR, Sokol RJ, Russell DW. Identification of a new inborn error in bile acid synthesis: mutation of the oxysterol 7alphahydroxylase gene causes severe neonatal liver disease. J Clin Invest 1998; 102(9): 1690-703.

12 Li-Hawkins J, Lund EG, Turley SD, Russell DW. Disruption of the oxysterol 7alpha-hydroxylase gene in mice. J Biol Chem 2000;275(22):16536-42.

13 Clayton PT, Leonard JV, Lawson AM, Setchell KD, Andersson S, Egestad B Sjovall J. Familial giant cell hepatitis associated with synthesis of 3 beta, 7 alpha-dihydroxy- and 3 beta,7 alpha, 12 alpha-trihydroxy-5-cholenoic acids. J Clin Invest 1987:79(4):1031-8.

14 Buchmann MS, Kvittingen EA, Nazer H, Gunasekaran T, Clayłon PT, Sjovall J, Bjorkhem I. Lack of 3 beta-hydroxy-delta 5-C27-steroid dehydrogenase/isomerase in fibroblasts from a child with urinary excretion of 3 beta-hydroxy-delta 5-bile acids. A new inborn error of metabolism. J Clin Invest 1990;86(6):2034-7.

15 Horslen SP, Lawson AM, Malone M, Clayton PT. 3 beta-hydroxy-delta 5 C27-steroid dehydrogenase deficiency: effect of chenodeoxycholic acid therapy on liver histology. J Inherit Metab Dis 1992;15(1):38-46.

16 Schwarz M, Wright AC, Davis DL, Nazer H, Bjorkhem I, Russell DW. The bile acid synthetic gene 3beta-hydroxy-Delta(5)-C(27)-steroid oxidoreductase is mutated in progressive intrahepatic cholestasis. $J$ Clin Invest 2000; 106(9): 1175-84.

17 Ichimiya H, Egestad B, Nazer H, Baginski ES, Clayton PT, Sjovall J. Bile acids and bile alcohols in a child with hepatic 3 beta-hydroxy-delta 5-C27-steroid dehydrogenase deficiency: effects of chenodeoxycholic acid treatment. J Lipid Res 1991;32(5):829-41.

18 Setchell KD, Suchy FJ, Welsh MB, Zimmer-Nechemias L, Heubi J, Balistreri WF. Delta 4-3-oxosteroid 5 beta-reductase deficiency described in identical twins with neonatal hepatitis. A new inborn error in bile acid synthesis. J Clin Invest 1988;82(6):2148-57.

19 Kondo KH, Kai MH, Setoguchi Y, Eggertsen G, Sjoblom P, Setoguchi T, Okuda KI, Bjorkhem I. Cloning and expression of cDNA of human delta 4-3 oxosteroid 5 beta-reductase and substrate specificity of the expressed enzyme. Eur J Biochem 1994;219(1-2):357-63.

20 Charbonneau A, Luu-The V. Assignment of steroid 5beta-reductase (SRD5B1) and its pseudogene (SRD5BP1) to human chromosome bands $7 q 32->q 33$ and $1 q 23->q 25$, respectively, by in situ hybridization. Cytogenet Cell Genet 1999;84(1-2):105-6.

21 Sawada N, Sakaki T, Kitanaka S, Kato S, Inouye K. Structure-function analysis of CYP27B1 and CYP27A1. Studies on mutants from patients with vitamin D-dependent rickets type I (VDDR-I) and cerebrotendinous xanthomatosis (CTX). Eur J Biochem 2001;268(24):6607-15

22 Hanson RF, Isenberg JN, Williams GC, Hachey D, Szczepanik P, Klein PD, Sharp HL. The metabolism of 3alpha, 7alpha, 12alpha-trihydroxy-5betacholestan-26-oic acid in two siblings with cholestasis due to intrahepatic bile duct anomalies. An apparent inborn error of cholic acid synthesis. J Clin Invest 1975;56(3):577-87.

23 Suzuki $Y$, Jiang LL, Souri M, Miyazawa S, Fukuda S, Zhang Z, Une $M$, Shimozawa N, Kondo N, Orii T, Hashimoto T. D-3-hydroxyacyl-CoA dehydratase/D-3-hydroxyacyl-CoA dehydrogenase bifunctional protein deficiency: a newly identified peroxisomal disorder. Am J Hum Genet 1997;61(5): 1 1 153-62.

24 Ferdinandusse S, Denis S, Clayton PT, Graham A, Rees JE, Allen JT, McLean BN, Brown AY, Vreken P, Waterham HR, Wanders RJ. Mutations in the gene encoding peroxisomal alpha-methylacyl-CoA racemase cause adult-onset sensory motor neuropathy. Nat Genet 2000;24(2):188-91.

25 Une M, Konishi M, Suzuki Y, Akaboshi S, Yoshii M, Kuramoto T, Fujimura K. Bile acid profiles in a peroxisomal D-3-hydroxyacyl-CoA dehydratase/D-3hydroxyacyl-CoA dehydrogenase bifunctional protein deficiency. J Biochem (Tokyo) 1997;122(3):655-8

26 Watkins PA, Chen WW, Harris CJ, Hoefler G, Hoefler S, Blake DC Jr, Balfe A, Kelley RI, Moser AB, Beard ME. Peroxisomal bifunctional enzyme deficiency. J Clin Invest 1989;83(3):771-7.

27 Gould Sj, Valle D. Peroxisome biogenesis disorders: genetics and cell biology. Trends Genet 2000;16(8):340-5.

28 Beil U, Crouse JR, Einarsson K, Grundy SM. Effects of interruption of the enterohepatic circulation of bile acids on the transport of very low densitylipoprotein triglycerides. Metabolism 1982;31(5):438-44.

29 Kast HR, Nguyen CM, Sinal CJ, Jones SA, Laffitte BA, Reue K, Gonzalez FJ, Willson TM, Edwards PA. Farnesoid X-activated receptor induces apolipoprotein C-II transcription: a molecular mechanism linking plasma triglyceride levels to bile acids. Mol Endocrinol 2001;15(10):1720-8.

30 Carlton VE, Harris BZ, Puffenberger EG, Batta AK, Knisely AS, Robinson DL, Strauss KA, Shneider BL, Lim WA, Salen G, Morton DH, Bull LN. Complex inheritance of familial hypercholanemia with associated mutations in TJP2 and BAAT. Nat Genet 2003;34(1):91-6.

31 Jesaitis LA, Goodenough DA. Molecular characterization and tissue distribution of ZO-2, a tight junction protein homologous to ZO-1 and the Drosophila discs-large tumor suppressor protein. J Cell Biol 1994; 124(6):949-61.

32 McCarthy KM, Francis SA, McCormack JM, Lai J, Rogers RA, Skare IB, Lynch RD, Schneeberger EE. Inducible expression of claudin-1-myc but not
occludin-VSV-G results in aberrant tight junction strand formation in MDCK cells. J Cell Sci 2000;113(Pt 19):3387-98.

33 Noe J, Stieger B, Meier PJ. Functional expression of the canalicular bile salt export pump of human liver. Gastroenterology 2002;123(5):1659-66.

34 Zhu QS, Xing W, Qian B, von Dippe P, Shneider BL, Fox VL, Levy D. Inhibition of human $\mathrm{m}$-epoxide hydrolase gene expression in a case of hypercholanemia. Biochim Biophys Acta 2003; 1638(3):208-16.

35 Floreani A, Molaro M, Mottes M, Sangalli A, Baragiotta A, Roda A, Naccarato $R$, Clementi $M$. Autosomal dominant benign recurrent intrahepatic cholestasis (BRIC) unlinked to $18 q 21$ and $2 q 24$. Am J Med Genet 2000;95(5):450-3

36 Clayton RJ, Iber FL, Ruebner BH, McKusick VA. Byler disease. Fatal familial intrahepatic cholestasis in an Amish kindred. Am J Dis Child 1969;117(1):112-24.

37 Strautnieks SS, Kagalwalla AF, Tanner MS, Gardiner RM, Thompson RJ. Locus heterogeneity in progressive familial intrahepatic cholestasis. J Med Genet 1996:33(10):833-6.

38 Houwen RH, Baharloo S, Blankenship K, Raeymaekers P, Juyn J, Sandkuij LA, Freimer NB. Genome screening by searching for shared segments: mapping a gene for benign recurrent intrahepatic cholestasis. Nat Genet 1994;8(4):380-6

39 Summerskill WHJ, Walshe JM. Benign recurrent intrahepatic obstructive jaundice. Lancet 1959;ii:686-90.

40 Nielsen IM, Ornvold K, Jacobsen BB, Ranek L. Fatal familial cholestatic syndrome in Greenland Eskimo children. Acta Paediatr Scand 1986:75(6):1010-6.

41 Eiberg H, Nielsen IM. Linkage of cholestasis familiaris groenlandica/Bylerlike disease to chromosome 18. Int J Circumpolar Health 2000;59:57-62.

42 Klomp LW, Bull LN, Knisely AS, Der Doelen MA, Juijn JA, Berger R, Forget S, Nielsen IM, Eiberg $\mathrm{H}$, Houwen RH. A missense mutation in $\mathrm{FICl}$ is associated with greenland familial cholestasis. Hepatology 2000;32(6):1337-41

43 Chen HL, Chang PS, Hsu HC, Ni YH, Hsu HY, Lee JH, Jeng YM, Shau WY, Chang MH. FICl and BSEP defects in Taiwanese patients with chronic intrahepatic cholestasis with low gamma-glutamyltranspeptidase levels. J Pediatr 2002;140(1):119-24.

44 Klomp LW, Vargas JC, van Mil SW, Pawlikowska L, Strautnieks SS, van Eijk MJ, Juijn JA, Pabon-Pena C, Smith LB, DeYoung JA, Byrne JA, Gombert J, van der BG, Berger R, Jankowska I, Pawlowska J, Villa E, Knisely AS, Thompson RJ, Freimer NB, Houwen RH, Bull LN Characterization of mutations in ATP8B1 associated with hereditary cholestasis. Hepatology 2004;40(1):27-38

45 Egawa H, Yorifuji T, Sumazaki R, Kimura A, Hasegawa M, Tanaka K. Intractable diarrhea after liver transplantation for Byler's disease: successful treatment with bile adsorptive resin. Liver Transpl 2002;8(8):714-6.

46 Lykavieris $\mathbf{P}$, van Mil S, Cresteil D, Fabre M, Hadchouel M, Klomp L, Bernard $O$, Jacquemin E. Progressive familial intrahepatic cholestasis type and extrahepatic features: no catch-up of stature growth, exacerbation of diarrhea, and appearance of liver steatosis after liver transplantation. $J$ Hepatol 2003;39(3):447-52.

47 Tygstrup N, Steig BA, Juijn JA, Bull LN, Houwen RH. Recurrent familial intrahepatic cholestasis in the Faeroe Islands. Phenotypic heterogeneity but genetic homogeneity. Hepatology 1999;29(2):506-8.

48 van Ooteghem NA, Klomp LW, Berge-Henegouwen GP, Houwen RH. Benign recurrent intrahepatic cholestasis progressing to progressive familial intrahepatic cholestasis: low GGT cholestasis is a clinical continuum. $J$ Hepatol 2002;36(3):439-43.

49 van Mil SW, van Oort MM, van den Berg IE, Berger R, Houwen RH, Klomp LW. FICl is expressed at apical membranes of different epithelial cells in the digestive tract and is induced in the small intestine during postnatal development of mice. Pediatr Res 2004;56(6):981-7.

50 Eppens EF, van Mil SW, de Vree JM, Mok KS, Juijn JA, Oude Elferink RP, Berger R, Houwen RH, Klomp LW. FICl, the protein affected in two forms of hereditary cholestasis, is localized in the cholangiocyte and the canalicular membrane of the hepatocyte. J Hepatol 2001;35(4):436-43

51 Ujhazy P, Ortiz D, Misra S, Li S, Moseley J, Jones H, Arias IM. Familial intrahepatic cholestasis 1: studies of localization and function. Hepatology 2001;34(4 Pt 1):768-75

52 Knisely AS. Progressive familial intrahepatic cholestasis: a personal perspective. Pediatr Dev Pathol 2000;3(2):113-25.

53 Pawlikowska L, Groen A, Eppens EF, Kunne C, Ottenhoff R, Looije N, Knisely AS, Killeen NP, Bull LN, Elferink RP, Freimer NB. A mouse genetic model for familial cholestasis caused by ATP8B1 mutations reveals perturbed bile salt homeostasis but no impairment in bile secretion. Hum Mol Genet 2004; 13(8):881-92

54 Hua Z, Fatheddin P, Graham TR. An essential subfamily of Drs $2 p$-related Ptype ATPases is required for protein trafficking between Golgi complex and endosomal/vacuolar system. Mol Biol Cell 2002;13(9):3162-77.

55 Pomorski T, Lombardi R, Riezman H, Devaux PF, van Meer G, Holthuis JC. Drs2p-related P-type ATPases Dnflp and Dnf2p are required for phospholipid translocation across the yeast plasma membrane and serve a role in endocytosis. Mol Biol Cell 2003;14(3):1240-54.

56 Tang X, Halleck MS, Schlegel RA, Williamson P. A subfamily of P-type ATPases with aminophospholipid transporting activity. Science 1996;272(5267): 1495-7

57 Siegmund A, Grant A, Angeletti C, Malone L, Nichols JW, Rudolph HK. Loss of Drs2 $p$ does not abolish transfer of fluorescence-labeled phospholipids across the plasma membrane of Saccharomyces cerevisiae. J Biol Chem 1998;273(51):34399-405

58 Knisely AS, Meier Y, Stieger B, Portmann BC, Rayner AC, Strautnieks S, Thompson R, Houwen RH, Klomp L, Bull L. Immunohistochemically 
recognized bile salt export protein is unremarkably expressed at the canaliculus in persons with ATP8B1 disease. Hepatology 2003;38:390A.

59 van Mil SW, Klomp LW, Bull LN, Houwen RH. FIC1 disease: a spectrum of intrahepatic cholestatic disorders. Semin Liver Dis 2001;21(4):535-44.

60 Chen F, Ananthanarayanan M, Emre S, Neimark E, Bull LN, Knisely AS, Strautnieks SS, Thompson RJ, Magid MS, Gordon R, Balasubramanian N, Suchy FJ, Shneider BL. Progressive familial intrahepatic cholestasis, type 1, is associated with decreased farnesoid X receptor activity. Gastroenterology 2004; 126(3):756-64.

61 Oelkers P, Kirby LC, Heubi JE, Dawson PA. Primary bile acid malabsorption caused by mutations in the ileal sodium-dependent bile acid transporter gene (SLC10A2). J Clin Invest 1997;99(8): 1880-7.

62 Strautnieks SS, Kagalwalla AF, Tanner MS, Knisely AS, Bull L, Freimer N, Kocoshis SA, Gardiner RM, Thompson RJ. Identification of a locus for progressive familial intrahepatic cholestasis PFIC2 on chromosome 2q24. Am J Hum Genet 1997;61(3):630-3

63 Strautnieks SS, Bull LN, Knisely AS, Kocoshis SA, Dahl N, Arnell H, Sokal E, Dahan K, Childs S, Ling V, Tanner MS, Kagalwalla AF, Nemeth A Pawlowska J, Baker A, Mieli-Vergani G, Freimer NB, Gardiner RM, Thompson RJ. A gene encoding a liver-specific $A B C$ transporter is mutated in progressive familial intrahepatic cholestasis. Nat Genet 1998;20(3):233-8.

64 Byrne JA, Strautnieks SS, Mieli-Vergani G, Higgins CF, Linton KJ Thompson RJ. The human bile salt export pump: characterization of substrate specificity and identification of inhibitors. Gastroenterology 2002;123(5): 1649-58.

65 Gerloff T, Stieger B, Hagenbuch B, Madon J, Landmann L, Roth J, Hofmann AF, Meier PJ. The sister of P-glycoprotein represents the canalicular bile salt export pump of mammalian liver. J Biol Chem 1998;273(16): 10046-50.

66 Green RM, Hoda F, Ward KL. Molecular cloning and characterization of the murine bile salt export pump. Gene 2000;241(1):117-23.

67 Wang R, Salem M, Yousef IM, Tuchweber B, Lam P, Childs SJ, Helgason CD, Ackerley C, Phillips MJ, Ling V. Targeted inactivation of sister of Pglycoprotein gene (spgp) in mice results in nonprogressive but persistent intrahepatic cholestasis. Proc Natl Acad Sci U S A 2001 98(4):2011-6.

68 Jansen PL, Strautnieks SS, Jacquemin E, Hadchouel M, Sokal EM, Hooiveld GJ, Koning JH, Jager-Krikken A, Kuipers F, Stellaard F, Biileveld CM, Gouw A, Van Goor H, Thompson RJ, Muller M. Hepatocanalicular bile salt export pump deficiency in patients with progressive familial intrahepatic cholestasis. Gastroenterology 1999; 117(6):1370-9.

69 Thompson R, Strautnieks S. BSEP: function and role in progressive familial intrahepatic cholestasis. Semin Liver Dis 2001;21(4):545-50.

70 Wang L, Soroka CJ, Boyer JL. The role of bile salt export pump mutations in progressive familial intrahepatic cholestasis type II. J Clin Invest 2002;110(7):965-72.

71 Plass JR, Mol O, Heegsma J, Geuken M, de Bruin J, Elling G, Muller M, Faber KN, Jansen PL. A progressive familial intrahepatic cholestasis type 2 mutation causes an unstable, temperature-sensitive bile salt export pump. J Hepatol 2004;40(1):24-30.

72 Denning GM, Anderson MP, Amara JF, Marshall J, Smith AE, Welsh MJ. Processing of mutant cystic fibrosis transmembrane conductance regulator is temperature-sensitive. Nature 1992;358(6389):761-4.

73 Sharma M, Benharouga M, Hu W, Lukacs GL. Conformational and temperature-sensitive stability defects of the delta F508 cystic fibrosis transmembrane conductance regulator in post-endoplasmic reticulum compartments. J Biol Chem 2001;276(12):8942-50.

74 Strautnieks S, Byrne JA, Knisely AS, Bull L, Sokal E, Lacaille F, Vergani G, Thompson R. There must be a third locus for low GGT PFIC. Hepatology 2001;34:240A

75 van Mil SW, van der Woerd WL, van der Brugge G, Sturm E, Jansen PL, Bull LN, van den Berg IE, Berger R, Houwen RH, Klomp LW. Benign recurrent intrahepatic cholestasis type 2 is caused by mutations in $A B C B 11$ Gastroenterology 2004;127(2):379-84.

76 Carey MC, Small DM. The physical chemistry of cholesterol solubility in bile. Relationship to gallstone formation and dissolution in man. J Clin Invest 1978;61(4):998-1026.

77 de Vree JM, Jacquemin E, Sturm E, Cresteil D, Bosma PJ, Aten J, Deleuze JF, Desrochers M, Burdelski M, Bernard O, Oude Elferink RP, Hadchouel M Mutations in the MDR3 gene cause progressive familial intrahepatic cholestasis. Proc Natl Acad Sci U S A 1998;95(1):282-7.

78 Deleuze JF, Jacquemin E, Dubuisson C, Cresteil D, Dumont M, Erlinger S, Bernard O, Hadchouel M. Defect of multidrug-resistance 3 gene expression in a subtype of progressive familial intrahepatic cholestasis. Hepatology 1996;23(4):904-8

79 Jacquemin E, de Vree JM, Cresteil D, Sokal EM, Sturm E, Dumont M, Scheffer GL, Paul M, Burdelski M, Bosma PJ, Bernard O, Hadchouel M, Elferink RP. The wide spectrum of multidrug resistance 3 deficiency: from neonatal cholestasis to cirrhosis of adulthood. Gastroenterology 2001; 120(6): 1448-58

80 Smit JJ, Schinkel AH, Oude Elferink RP, Groen AK, Wagenaar E, van Deemter L, Mol CA, Ottenhoff R, van der Lugt NM, van Roon MA. Homozygous disruption of the murine mdr2 P-glycoprotein gene leads to a complete absence of phospholipid from bile and to liver disease. Cell 1993;75(3):451-62.

81 Ruetz S, Gros P. Phosphatidylcholine translocase: a physiological role for the mdr2 gene. Cell 1994;77(7):1071-81.

82 van Nieuwkerk CM, Elferink RP, Groen AK, Ottenhoff R, Tytgat GN, Dingemans KP, van den Bergh Weerman MA, Offerhaus GJ. Effects of ursodeoxycholate and cholate feeding on liver disease in FVB mice with a disrupted mdr2 P-glycoprotein gene. Gastroenterology 1996;111(1):165-71.

83 Bacq Y, Myara A, Brechot MC, Hamon C, Studer E, Trivin F, Metman EH. Serum conjugated bile acid profile during intrahepatic cholestasis of pregnancy. J Hepatol 1995;22(1):66-70.

84 Laatikainen T, Tulenheimo A. Maternal serum bile acid levels and fetal distress in cholestasis of pregnancy. Int J Gynaecol Obstet 1984;22(2):91-4.

85 Lammert F, Marschall HU, Glantz A, Matern S. Intrahepatic cholestasis of pregnancy: molecular pathogenesis, diagnosis and management. J Hepatol 2000;33(6):1012-21.

86 Kreek MJ. Female sex steroids and cholestasis. Semin Liver Dis $1987 ; 7(1): 8-23$

87 Reyes H, Sjovall J. Bile acids and progesterone metabolites in intrahepatic cholestasis of pregnancy. Ann Med 2000;32(2):94-106.

88 Geier A, Dietrich CG, Gerloff T, Haendly J, Kullak-Ublick GA, Stieger B Meier PJ, Matern S, Gartung C. Regulation of basolateral organic anion transporters in ethinylestradiol-induced cholestasis in the rat. Biochim Biophys Acta 2003;1609(1):87-94.

89 Simon FR, Fortune J, Iwahashi M, Gartung C, Wolkoff A, Sutherland E. Ethinyl estradiol cholestasis involves alterations in expression of liver sinusoidal transporters. Am J Physiol 1996;271(6 Pt 1):G1043-52.

90 de Pagter AG, Berge Henegouwen GP, Bokkel Huinink JA, Brandt KH. Familial benign recurrent intrahepatic cholestasis. Interrelation with intrahepatic cholestasis of pregnancy and from oral contraceptives? Gastroenterology 1976;71(2):202-7

91 Jacquemin E, Cresteil D, Manouvrier S, Boute O, Hadchouel M. Heterozygous non-sense mutation of the MDR3 gene in familial intrahepatic cholestasis of pregnancy. Lancet 1999;353(9148):210-11.

92 Dixon PH, Weerasekera N, Linton KJ, Donaldson O, Chambers J, Egginton E, Weaver J, Nelson-Piercy C, de Swiet M, Warnes G, Elias E, Higgins CF, Johnston DG, McCarthy MI, Williamson C. Heterozygous MDR3 missense mutation associated with intrahepatic cholestasis of pregnancy: evidence for a defect in protein trafficking. Hum Mol Genet 2000;9(8):1209-17.

93 Mullenbach R, Linton KJ, Wiltshire S, Weerasekera N, Chambers J, Elias E, Higgins CF, Johnston DG, McCarthy MI, Williamson C. ABCB4 gene sequence variation in women with intrahepatic cholestasis of pregnancy. J Med Genet 2003:40(5):e70.

94 Savander M, Ropponen A, Avela K, Weerasekera N, Cormand B, Hirvioja ML, Riikonen S, Ylikorkala O, Lehesjoki AE, Williamson C Aittomaki K. Genetic evidence of heterogeneity in intrahepatic cholestasis of pregnancy. Gut 2003;52(7):1025-9.

95 Reyes H, Gonzalez MC, Ribalta J, Aburto H, Matus C, Schramm G, Katz R, Medina E. Prevalence of intrahepatic cholestasis of pregnancy in Chile. Ann Intern Med 1978;88(4):487-93.

96 Laatikainen T, Ikonen E. Fetal prognosis in obstetric hepatosis. Ann Chir Gynaecol Fenn 1975;64(3):155-64

97 Macias RI, Pascual MJ, Bravo A, Alcalde MP, Larena MG, St Pierre MV, Serrano MA, Marin JJ. Effect of maternal cholestasis on bile acid transfer across the rat placenta-maternal liver tandem. Hepatology 2000;31(4):975-83

98 Serrano MA, Brites D, Larena MG, Monte MJ, Bravo MP, Oliveira N, Marin JJ. Beneficial effect of ursodeoxycholic acid on alterations induced by cholestasis of pregnancy in bile acid transport across the human placenta. J Hepatol 1998;28(5):829-39.

99 Mazzella G, Rizzo N, Azzaroli F, Simoni P, Bovicelli L, Miracolo A, Simonazzi G, Colecchia A, Nigro G, Mwangemi C, Festi D, Roda E, Nicola R, Francesco A, Patrizia S, Luciano B, Anna M, Giuliana S, Antonio C, Giovanni N, Constance M, Davide F, Enrico R. Ursodeoxycholic acid administration in patients with cholestasis of pregnancy: effects on primary bile acids in babies and mothers. Hepatology 2001;33(3):504-8.

100 Di Rocco M, Reboa E, Barabino A, Larnaout A, Canepa M, Savioli C, Cremonte $M$, Borrone $C$. Arthrogryposis, cholestatic pigmentary liver disease and renal dysfunction: report of a second family. Am J Med Genet 1990:37(2):237-40

101 Nezelof C, Dupart MC, Jaubert F, Eliachar E. A lethal familial syndrome associating arthrogryposis multiplex congenita, renal dysfunction, and a cholestatic and pigmentary liver disease. J Pediatr 1979;94(2):258-60.

102 Coleman RA, Van Hove JL, Morris CR, Rhoads JM, Summar ML. Cerebral defects and nephrogenic diabetes insipidus with the ARC syndrome: additional findings or a new syndrome (ARCC-NDI)? Am J Med Genet 1997;72(3):335-8.

103 Eastham KM, McKiernan PJ, Milford DV, Ramani P, Wyllie J, van't Hoff W, Lynch SA, Morris AA. ARC syndrome: an expanding range of phenotypes. Arch Dis Child 2001;85(5):415-20.

104 Gissen P, Johnson CA, Stapelbroek J, McKiernan PJ, International ARC Collaborating Group, Houwen R, Kelly DA, Maher ER. ARC syndrome is not allelic to PFIC I and II. Arch Dis Child 2003;88:A70.

105 Gissen P, Johnson CA, Morgan NV, Stapelbroek JM, Forshew T, Cooper WN, McKiernan PJ, Klomp LW, Morris AA, Wraith JE, McClean P, Lynch SA, Thompson RJ, Lo B, Quarrell OW, Di Rocco M, Trembath RC, Mandel H, Wali S, Karet FE, Knisely AS, Houwen RH, Kelly DA, Maher ER. Mutations in VPS33B, encoding a regulator of SNARE-dependent membrane fusion, cause arthrogryposis-renal dysfunction-cholestasis (ARC) syndrome. Nat Genet 2004;36(4):400-4.

106 Aagenaes $\mathbf{O}$. Hereditary cholestasis with lymphoedema (Aagenaes syndrome, cholestasis-lymphoedema syndrome). New cases and follow-up from infancy to adult age. Scand J Gastroenterol 1998;33(4):335-45.

107 Bull LN, Roche E, Song EJ, Pedersen J, Knisely AS, Der Hagen CB, Eiklid K, Aagenaes $O$, Freimer NB. Mapping of the locus for cholestasis-lymphedema syndrome (Aagenaes syndrome) to a 6.6-cM interval on chromosome 15q. Am J Hum Genet 2000;67(4):994-9. 
108 Fruhwirth M, Janecke AR, Muller T, Carlton VE, Kronenberg F, Offner F, Knisely AS, Geleff S, Song EJ, Simma B, Konigsrainer A, Margreiter R, van der Hagen CB, Eiklid K, Aagenaes O, Bull L, Ellemunter H. Evidence for genetic heterogeneity in lymphedema-cholestasis syndrome. J Pediatr 2003;142(4):441-7.

109 Shneider BL. Genetic cholestasis syndromes. J Pediatr Gastroenterol Nutr 1999;28(2):124-31.

110 Sigstad H, Aagenaes O, Bjorn-Hansen RW, Rootwelt K. Primary lymphoedema combined with hereditary recurrent intrahepatic cholestasis. Acta Med Scand 1970;188(3):213-9.

111 Drouin E, Russo P, Tuchweber B, Mitchell G, Rasquin-Weber A. North American Indian cirrhosis in children: a review of 30 cases. J Pediatr Gastroenterol Nutr 2000;31(4):395-404.

112 Jacquemin E. Progressive familial intrahepatic cholestasis. Genetic basis and treatment. Clin Liver Dis 2000;4(4):753-63.

113 Betard C, Rasquin-Weber A, Brewer C, Drouin E, Clark S, Verner A, Darmond-Zwaig C, Fortin J, Mercier J, Chagnon P, Fujiwara TM, Morgan K, Richter A, Hudson TJ, Mitchell GA. Localization of a recessive gene for North American Indian childhood cirrhosis to chromosome region 16q22 and identification of a shared haplotype. Am J Hum Genet 2000;67(1):222-8.

114 Chagnon P, Michaud J, Mitchell G, Mercier J, Marion JF, Drouin E, Rasquin Weber A, Hudson TJ, Richter A. A missense mutation (R565W) in cirhin (FU14728) in North American Indian childhood cirrhosis. Am J Hum Genet 2002;71(6):1443-9.

115 Smith TF, Gaitatzes C, Saxena K, Neer EJ. The WD repeat: a common architecture for diverse functions. Trends Biochem Sci 1999;24(5):181-5.

116 Chawla A, Repa JJ, Evans RM, Mangelsdorf DJ. Nuclear receptors and lipid physiology: opening the X-files. Science 2001;294(5548):1866-70.

117 Goodwin B, Jones SA, Price RR, Watson MA, McKee DD, Moore LB, Galardi C, Wilson JG, Lewis MC, Roth ME, Maloney PR, Willson TM, Kliewer SA. A regulatory cascade of the nuclear receptors FXR, SHP-1, and LRH-1 represses bile acid biosynthesis. Mol Cell 2000;6(3):517-26.

118 Redinger RN. Nuclear receptors in cholesterol catabolism: molecular biology of the enterohepatic circulation of bile salts and its role in cholesterol homeostasis. J Lab Clin Med 2003;142(1):7-20.

119 Denson LA, Sturm E, Echevarria W, Zimmerman TL, Makishima M, Mangelsdorf DJ, Karpen SJ. The orphan nuclear receptor, shp, mediates bile acid-induced inhibition of the rat bile acid transporter, ntcp. Gastroenterology 2001;121(1):140-7.

120 Laffitte BA, Kast HR, Nguyen CM, Zavacki AM, Moore DD, Edwards PA. Identification of the DNA binding specificity and potential target genes for the farnesoid X-activated receptor. J Biol Chem 2000;275(14):10638-47.

121 Lu T, Makishima M, Repa JJ, Schoonjans K, Kerr TA, Auwerx J, Mangelsdorf DJ. Molecular basis for feedback regulation of bile acid synthesis by nuclear receptors. Mol Cell 2000;6(3):507-15.

122 Ananthanarayanan M, Balasubramanian N, Makishima M, Mangelsdorf DJ, Suchy FJ. Human bile salt export pump promoter is transactivated by the farnesoid $X$ receptor/bile acid receptor. J Biol Chem $2001 ; 276(31): 28857-65$
123 Grober J, Zaghini I, Fujii H, Jones SA, Kliewer SA, Willson TM, Ono T, Besnard $P$. Identification of a bile acid-responsive element in the human ileal bile acid-binding protein gene. Involvement of the farnesoid X receptor/9cis-retinoic acid receptor heterodimer. J Biol Chem 1999;274(42):29749-54.

124 Sinal CJ, Tohkin M, Miyata M, Ward JM, Lambert G, Gonzalez FJ. Targeted disruption of the nuclear receptor FXR/BAR impairs bile acid and lipid homeostasis. Cell 2000;102(6):731-44.

125 Li YC, Wang DP, Chiang JY. Regulation of cholesterol 7 alpha-hydroxylase in the liver. Cloning, sequencing, and regulation of cholesterol 7 alphahydroxylase mRNA. J Biol Chem 1990;265(20):12012-9.

126 Gascon-Barre M, Demers C, Mirshahi A, Neron S, Zalzal S, Nanci A. The normal liver harbors the vitamin $D$ nuclear receptor in nonparenchymal and biliary epithelial cells. Hepatology 2003;37(5):1034-42.

127 Makishima M, Lu T, Xie W, Whitfield GK, Domoto H, Evans RM, Haussler MR, Mangelsdorf DJ. Vitamin D receptor as an intestinal bile acid sensor. Science 2002;296(5571):1313-6.

128 Staudinger JL, Goodwin B, Jones SA, Hawkins-Brown D, MacKenzie KI, LaTour A, Liu Y, Klaassen CD, Brown KK, Reinhard J, Willson TM, Koller BH, Kliewer SA. The nuclear receptor PXR is a lithocholic acid sensor that protects against liver toxicity. Proc Natl Acad Sci U S A 2001;98(6):3369-74.

129 Peet DJ, Turley SD, Ma W, Janowski BA, Lobaccaro JM, Hammer RE, Mangelsdorf DJ. Cholesterol and bile acid metabolism are impaired in mice lacking the nuclear oxysterol receptor LXR alpha. Cell 1998;93(5):693-704.

130 Crocenzi FA, Mottino AD, Cao J, Veggi LM, Pozzi EJ, Vore M, Coleman R, Roma MG. Estradiol-17beta-D-glucuronide induces endocytic internalization of Bsep in rats. Am J Physiol Gastrointest Liver Physiol 2003;285(2):G449-59.

131 Mottino AD, Cao J, Veggi LM, Crocenzi F, Roma MG, Vore M. Altered localization and activity of canalicular Mrp2 in estradiol-17beta-Dglucuronide-induced cholestasis. Hepatology 2002;35(6):1409-19.

132 Paulusma CC, Kothe MJ, Bakker CT, Bosma PJ, van Bokhoven I, van Marle J, Bolder U, Tytgat GN, Oude Elferink RP. Zonal down-regulation and redistribution of the multidrug resistance protein 2 during bile duct ligation in rat liver. Hepatology 2000;31(3):684-93.

133 Jansen PL, Muller M, Sturm E. Genes and cholestasis. Hepatology 2001;34(6):1067-74.

134 Xie W, Radominska-Pandya A, Shi Y, Simon CM, Nelson MC, Ong ES, Waxman DJ, Evans RM. An essential role for nuclear receptors SXR/PXR in detoxification of cholestatic bile acids. Proc Natl Acad Sci U S A 2001;98(6):3375-80.

135 Yu J, Lo JL, Huang L, Zhao A, Metzger E, Adams A, Meinke PT, Wright SD, Cui J. Lithocholic acid decreases expression of bile salt export pump through farnesoid $X$ receptor antagonist activity. J Biol Chem 2002;277(35):31441-7.

136 Ye S, Cole-Strauss AC, Frank B, Kmiec EB. Targeted gene correction: a new strategy for molecular medicine. Mol Med Today 1998;4(10):431-7.

\section{Opportunities for Associate Editors and Editorial Baord Members at the} Journal of Medical Genetics

With the forthcoming retirement of (a) Professor Charis Eng and Dr Willie Reardon as Associate Editors and (b) several Editorial Board Members, we are seeking applications from enthusiastic and supportive individuals who would wish to join the Journal of Medical Genetics Editorial team or Editorial Board.

Individuals wishing to be considered should send a brief CV with details of clinical and research expertise and a summary of what they consider they would contribute to the Journal (jmg@bmigroup.com). Informal enquiries to Eamonn Maher (E.R.Maher@bham.ac.uk). 